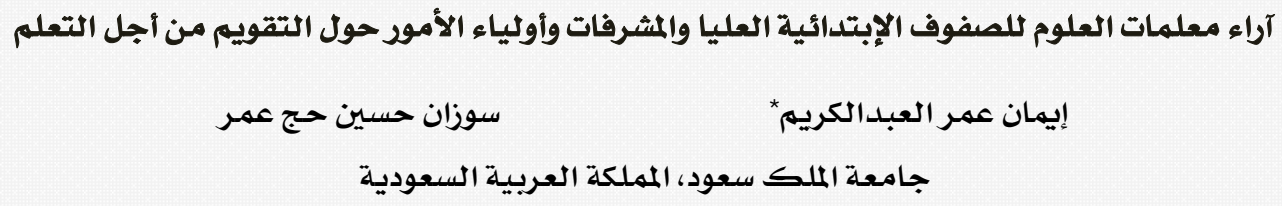

يعاني نظام التقويم المستمر المطبق على المرحلة الإبتدائية من بعض الخلل بسبب ميله إلى تقويم تعلم الطالبات بدلا من تحسين التعلم، إضافة

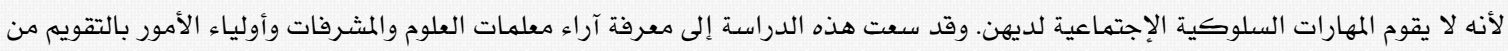

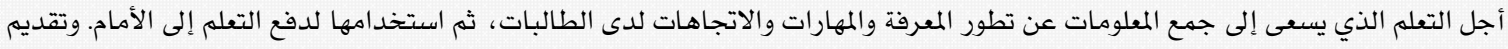

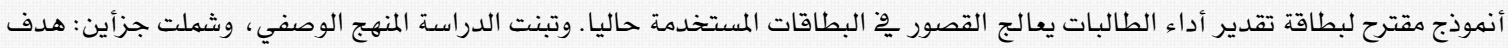

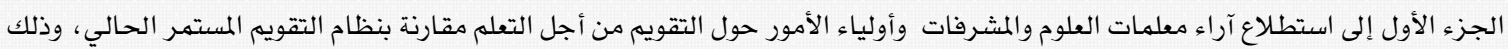
من خلال استبانة أعدت لهذا الغرض وتم التأكد من صدقها وثباتها. وهدف الجزء التهاء الثاني من الدراسة إلى التأكد من فعالية الأنموذج المقترح

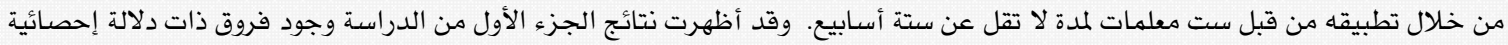

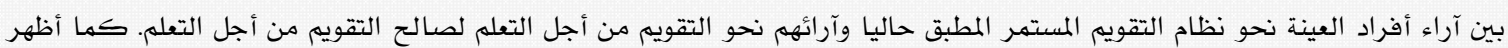

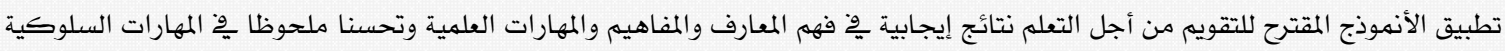

$$
\text { الإجتماعية.وخلصت الدراسة إلى مجموعة من التوصيات والمقترحات. }
$$$$
\text { كلمات مفتاحية : التقويم المستمر، التقويم من أجل التعلم، تدريس العلوم. }
$$

\title{
Perspectives of Primary School Science Teachers, Supervisors and Parents towards Assessment for Learning
}

\author{
Iman O. AIA bdulkarim*
} King Saud University, kingdom of Saudi A rabia

One of the major problems of the Continuous Assessment System (CAS) in elementary schools is that it assesses students' learning more than helping them improve their understanding and knowledge of scientific concepts and skills. It also does not assess their behavioral and social skills. This research aims to introduce assessment for learning, where the teacher gathers information about the student's current knowledge and skills then provides them with feedback to help them improve learning. The study consists of two parts: a survey of the science teachers, supervisors and parents' opinions in comparing the two assessment systems (tested for validity and stability). The second part was to apply assessment for learning in science dassrooms by six teachers for a period not less than six weeks. Interviews were used to collect data and a new form of report card was proposed to assess student performance. Findings indicate significant differences between assessment for learning and CAS in favor of the former. The teachers noticed positive results in the knowledge and understanding of scientific concepts and skills of the students, and a marked improvement in social and behavioral skills.

Keyw ords: Continuous assessment, assessment for learning, science education.

*iman_oabdul@yahoo.com 


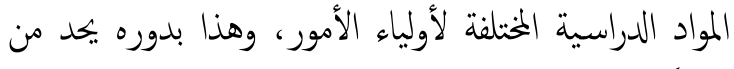

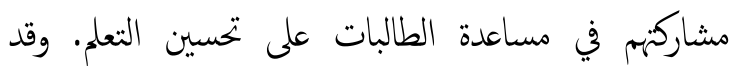

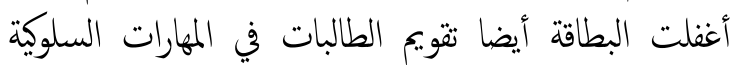
الاجتاعية مثل ضبط النفس واحتراهن للآخرين والمشاركة

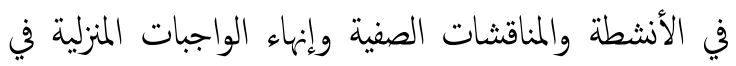

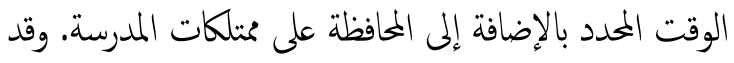

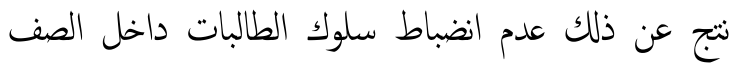

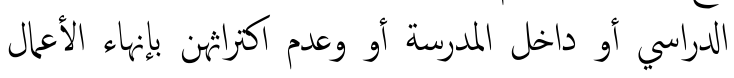

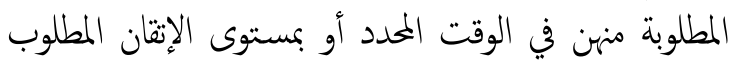

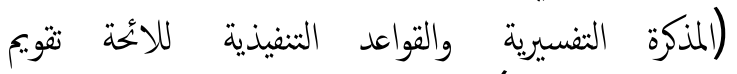

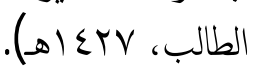

ويركز التقويم من أجل التعلم والذي يعرف أيضا بالتقويم

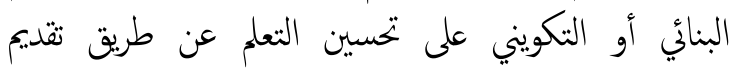

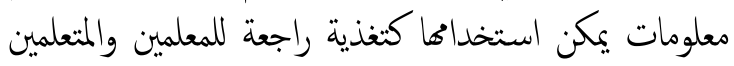
في تقويم أنقسهم وتقويم بعضهم البعض وفي تحسين التدريس

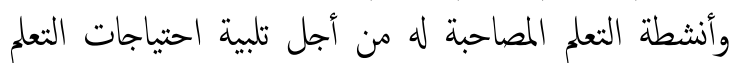
(Wiliam, Lee, Harrison, \& Black, 2004) خلال تحديد الفجوة بين ما تعرفه الطالبات والأهداف التي

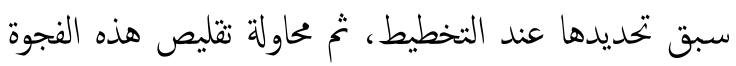

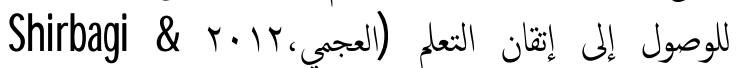
Bahman, 2008; Simpson-Beck, 2011; Wiliam, 2011;

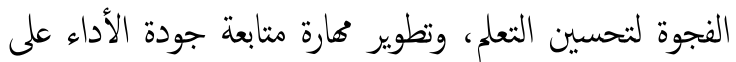

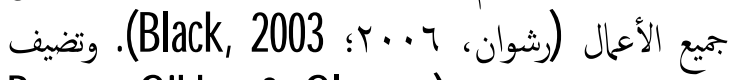

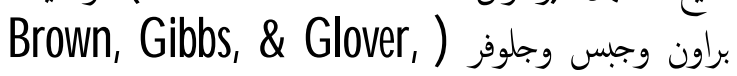
2003) شروطا أخرى للتغذية الراجعة الجيدة بأنها: مفصلة

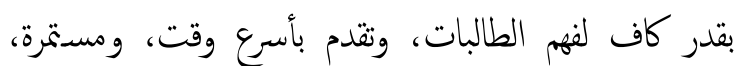

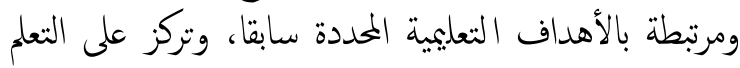

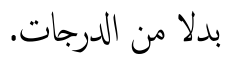

وتكون النغذية الراجعة ذات فعالية أكبر وذات أثر على زيادة

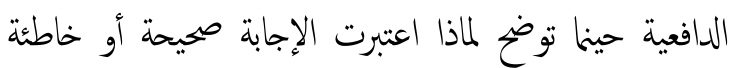

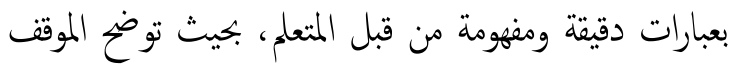

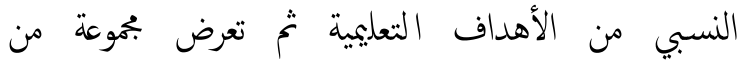
الاقتراحات لإغلاق الفجوة بين الأهداف المنشودة ومكان الطالبة في عملية النعلم ( Elshout-M ohr, 1994; Shute, (2008; Chappuis \& Stiggens, 2002 ما ذكره بلاك ووليام (Black \& Wiliam, 1998) نقلا
ظهرت توجحات قوية خلال الثمنينات من القرن الماضي نحو

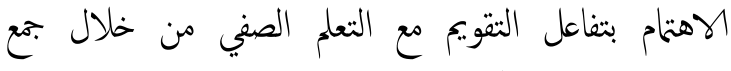

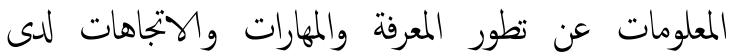

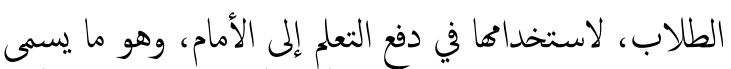

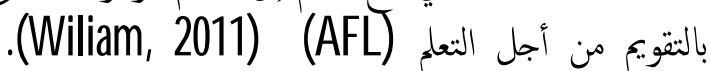
Assessment for Learning

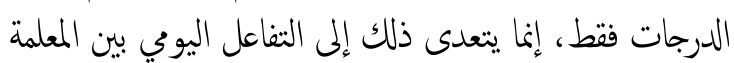

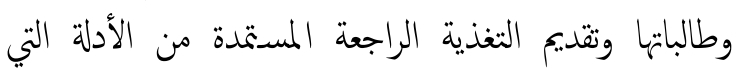

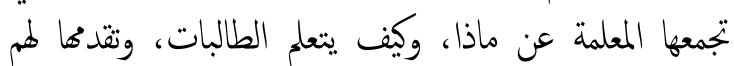

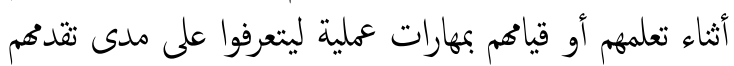
الدراسي وتحسين تعلمهم، أو للتعرف على الصعوبات التي تلئي توابجهم وتعيق التعلم ومن ثم اتخاذ قرار حول الخطوات التالية في التعلم، وهذا يحمل الطالبات قدرا من المسؤولية، بالإضافة

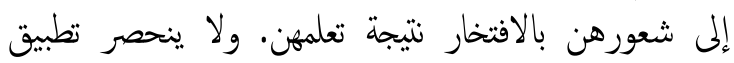

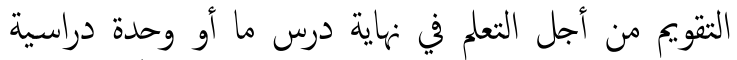

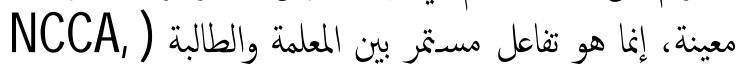
.2007

ويجب التميز بين نموذج التقويم من أجل التعلم ونموذج تقويم

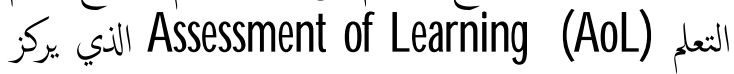
على التقويم المتوسط والتقويم طويل المدى، والذي ينفذ بعد

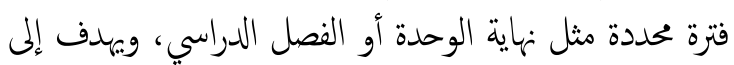

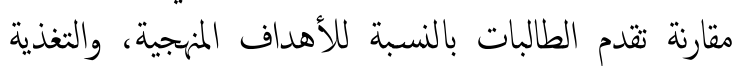

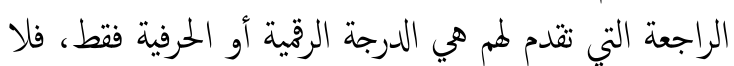

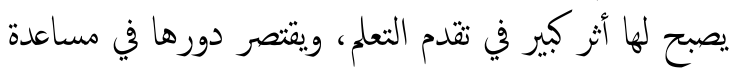

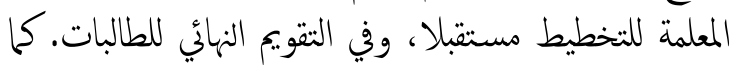

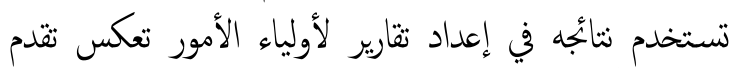
Black, Harrison, Lee, Marshall \& I أبناء .(Wiliam, 2003; NCCA, 2007; Wiliam, 2011 وقد سارت المملكة العربية السعودية مع بقية دول العالم في التوجه نحو التقويم من أجل التعلم عندما طبقت نظام التقويم

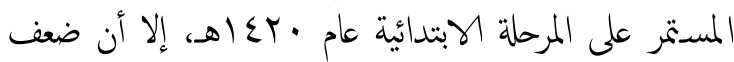

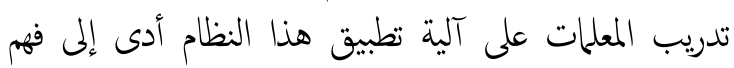

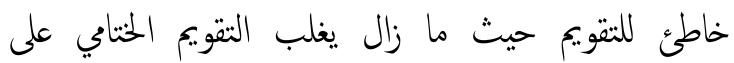

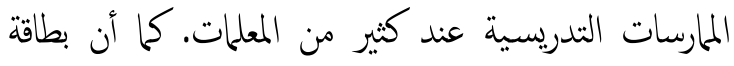
تقدير أداء الطالبات لا تحدد درجة فهمهن للمفاهيم العلمية

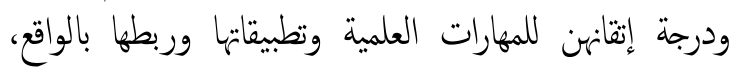
وبالتالي لا تقدم صورة حقيقية عن مستوى أداء الطالبات في وني 
نتائُ الدراسة أن تطبيق هذه الدورة إلى المستوى الأخير عند

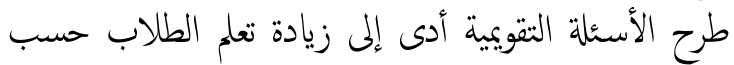

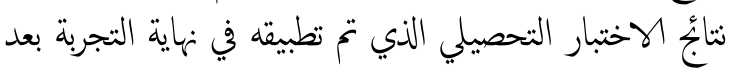

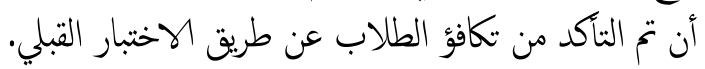
وتتضح أهمية التقويم الذاتي في تعويد المتعلمين على التأمل فيما

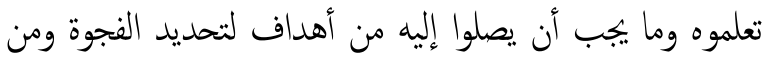

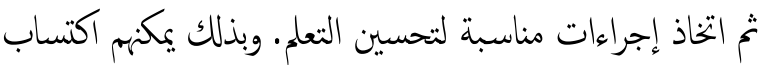

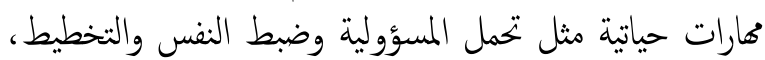

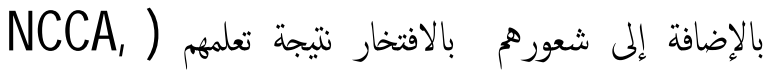

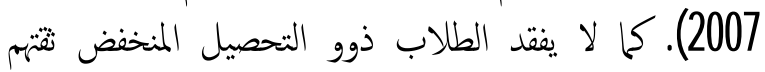

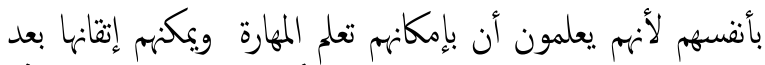
الفهم العميق وربطها بجياتهم اليومية (Yin, et. al., 2008). وأثار إيلشوت-مور (Elshout-Mohr, 1994) إلى أنه يصعب على الطالب التخلي عن المفاهيم البديلة المكتسبة سابقا

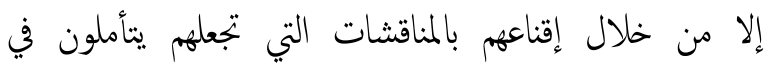

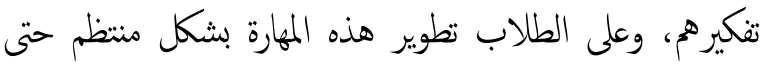
يمكنه الاستفادة من التغذية الراجعة الجيدة.

ودور الأقران في التقويم من أجل التعلم مشابه لدور المعلم رغخ

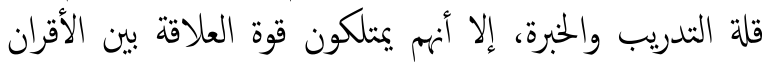

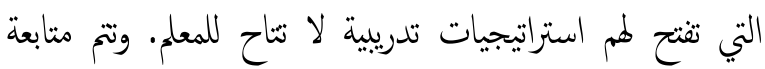

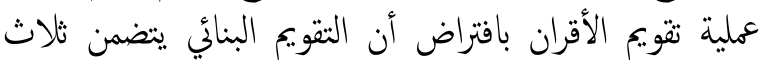

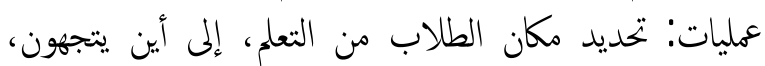
وكيف يصلون إلى أهدافهم. ويشارك الأقران في توجيه تعلم الئل

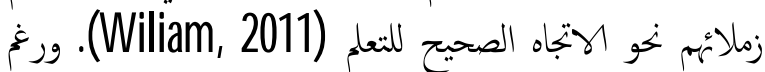
أن دراسة فولانت وبيكيت (Volantle \& Beckette, 2011)

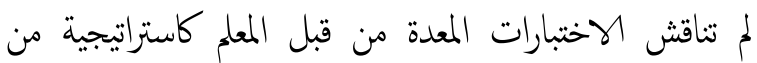

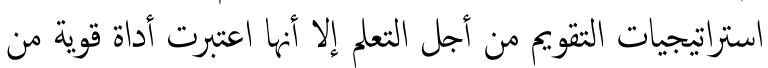
قبل وكوليك (Bangart-drowns, Kulik \& Kulik, 1991)

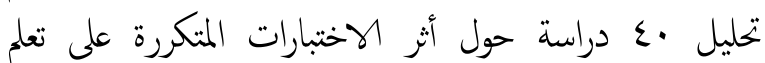

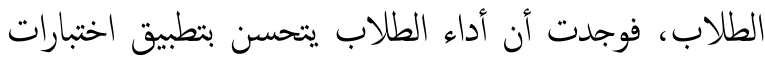

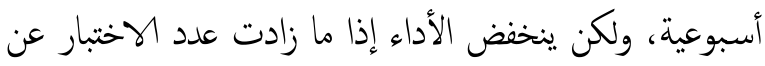

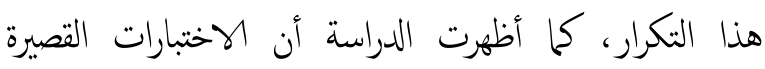

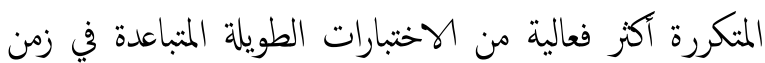

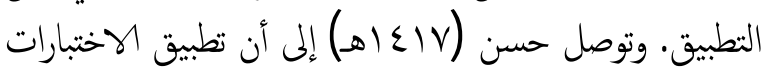

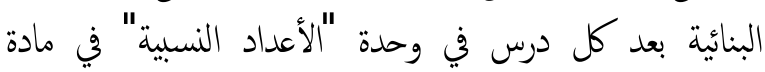
الرياضيات للصف الثاني المتوسط في مدينة أبها بالمملكة العربية
عن بتلر (Butler, 1988) الذي درس نأثنر أربعة أنواع من

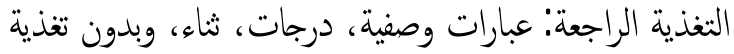

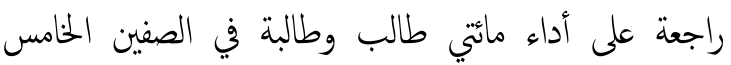

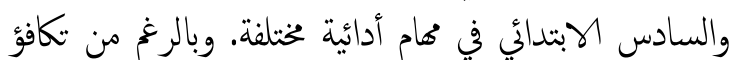

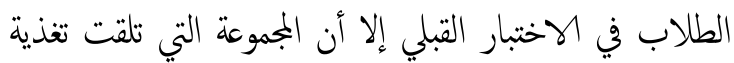

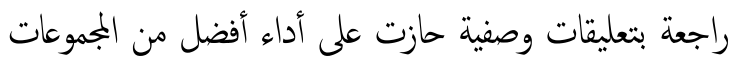
الأخرى التي لم يكن بينها اختلافات دالة إحصائيا. وتتم عملية التقويم من أجل التعلم بالاستعانة بعدة أدوات

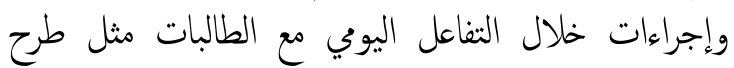

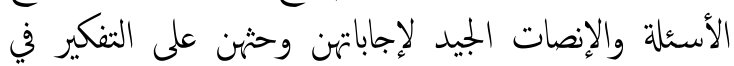
كيف توصلن إلى هذه الإجابة وتطوير محارات التفكير ما وراء

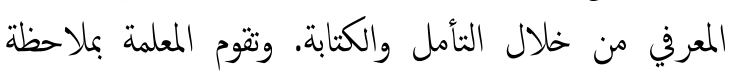
النشاط الصفي وخص الأعمال الكتابية والواجبات المنزلية التي ولتي

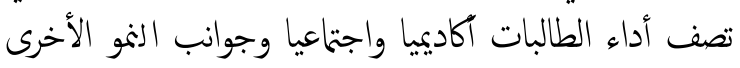

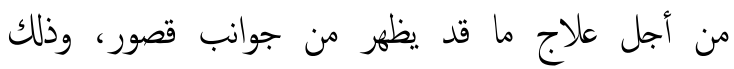

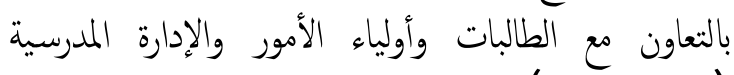
(خليل، ب... ب. ب).

وتتنوع استراتيجيات التقو.يم من أجل التعلم وقد اتضحت بعض

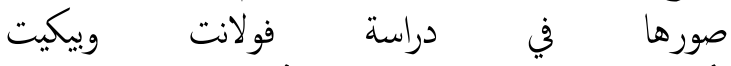
التي حاولت التعرف (Volante \& Beckette, 2011) على الممارسات التقويمية المطبقة على الصفوف المختلفة ابتداء

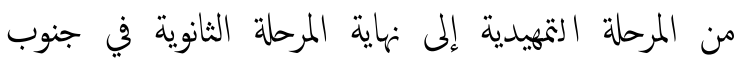

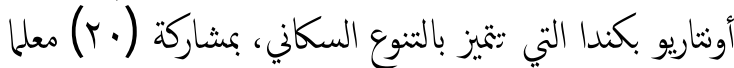

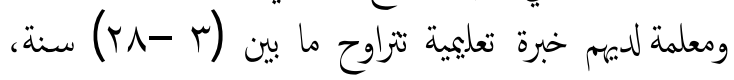

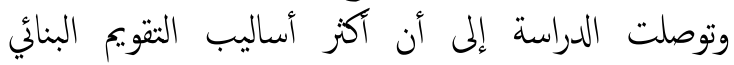

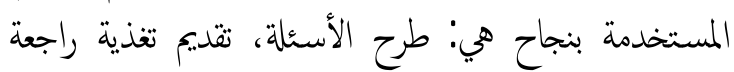
بدون درجات، الاستفادة من الاختبارات الوطنية لتحسين

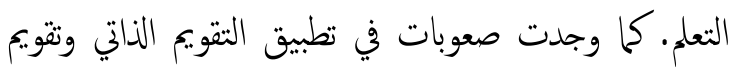

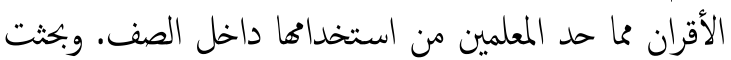

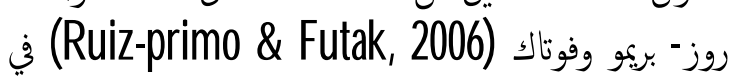
أثر الأسئلة المطروحة في التقويم البنائي غير الرسمي على تعلم

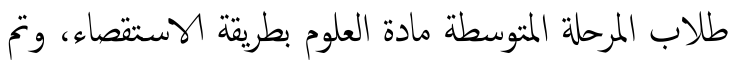

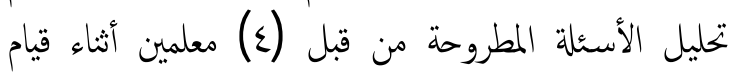
الطلاب باستقصاءات علمية وفق دورة ربن رباعية أعدها

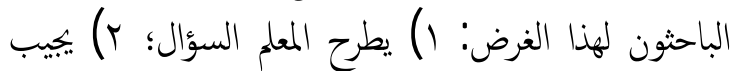

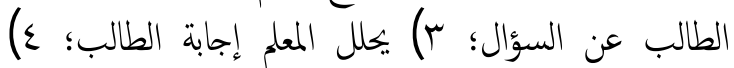

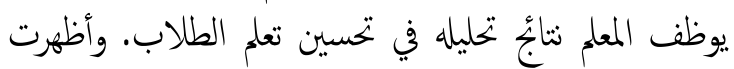




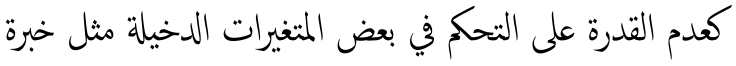

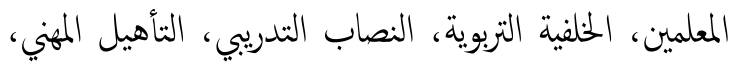

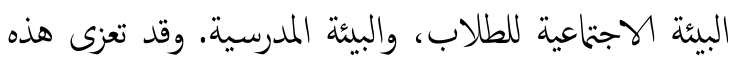

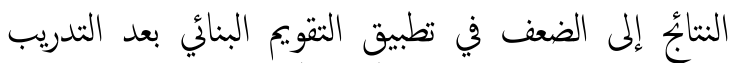

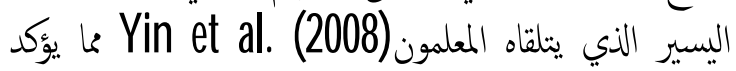

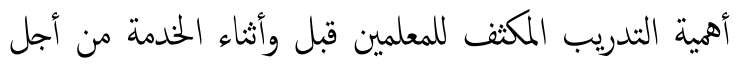

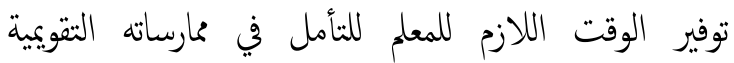

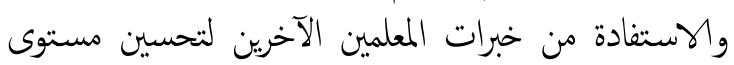

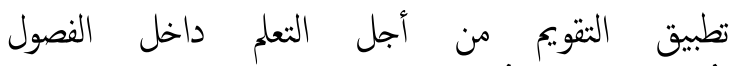

(Boston, 2002)

وبالرغخ من استخدام كثير من المعلمين والمعلمات للتقويم

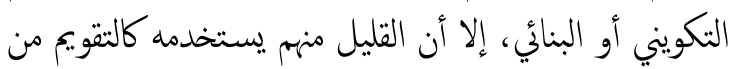

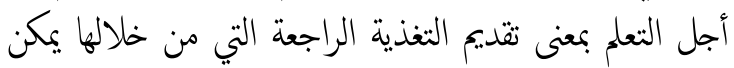

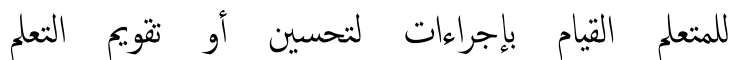
(Shirbagi \& Bahman, 2008) التعلم جزءا متكملا مع التدريس وليس معزولا عنه (رشوان ،

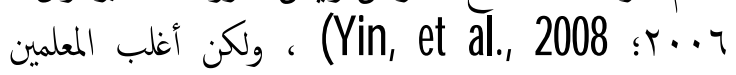

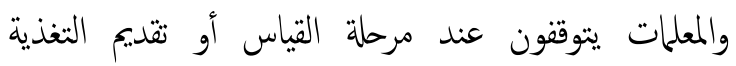

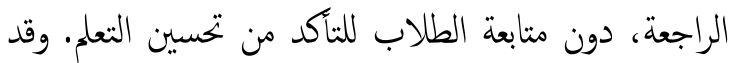

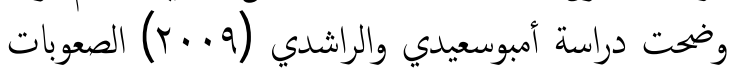
التي قد تعيق المعلمين من تطبيق التقويم البنائي و تتمثل أهمها

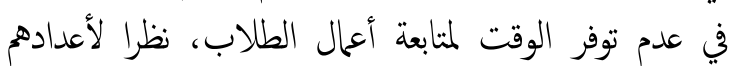

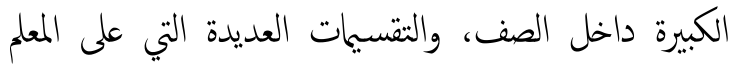

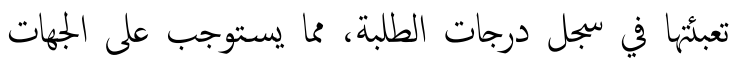
المسؤولة حل هذه المشكلات من أجل تحسين التعلم. ونظرا لقلة الدراسات العربية التي كنبت حول التقويم من أجل

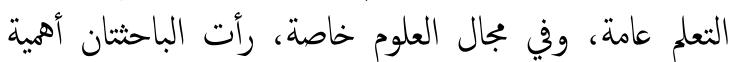
إجراء هذه الدراسة.

\section{مشكة الدراسة}

أظهرت الدراسة التي أجراها مكتب التربية والتعليم/ شمال

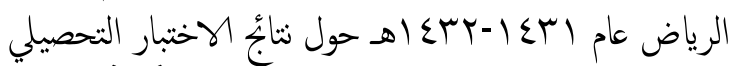

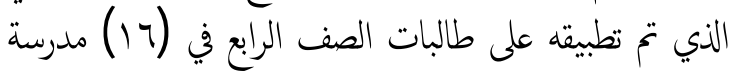

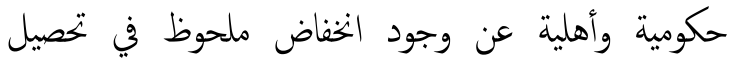

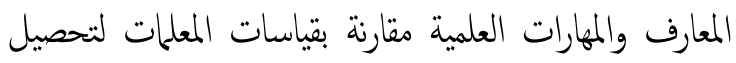

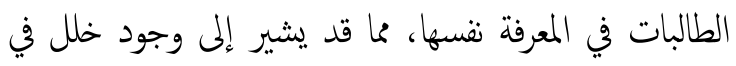

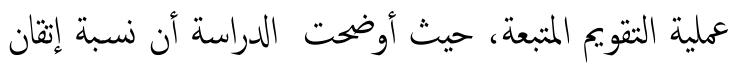

السعودية له تأثثر فعال وجوهري في زيادة تحصيل الطلاب. وقد

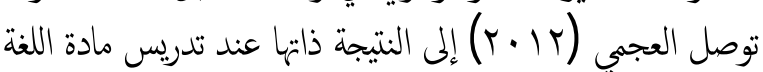
العربية (القراءة والكتابة) للصف السابع بدولة الفيجة ذابها الكويت. تكريس. ولمرد على ادعاءات بعض التربويين بأن الضغط على المدارس

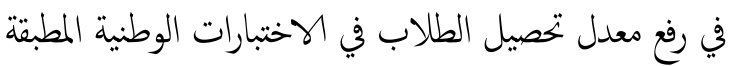

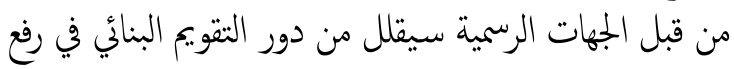

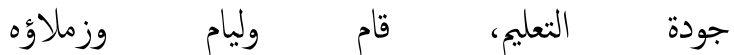
بتدريب (Wiliam, Lee, H arrison \& Black, 2004) ع r معلما ومعلمة خلال ستة أيام ونصف على أساسيات

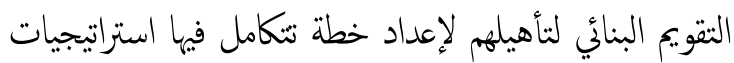

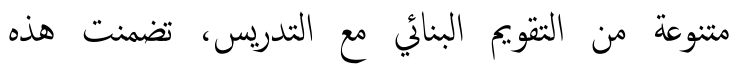

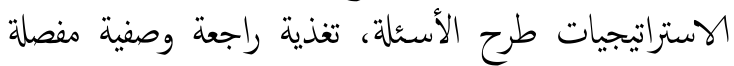

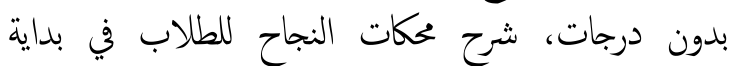

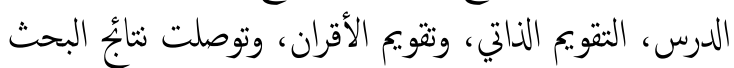

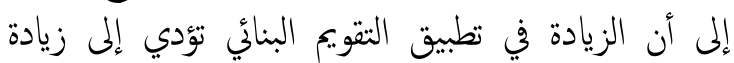

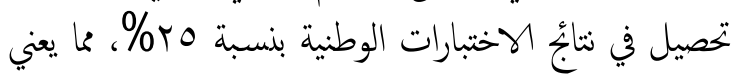

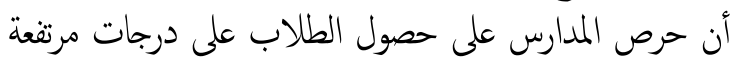
في الاختبارات الوطنية لا يتعارض مع دور التقويم البنائي في

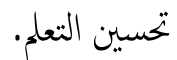

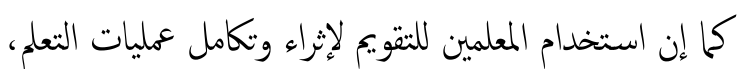
جعل الطلاب يشاركون بفعالية بأنشطة تقويمية يومية أثناء تعلمهم، مما حسن مستوى التحصيل الدراسي ودافعية

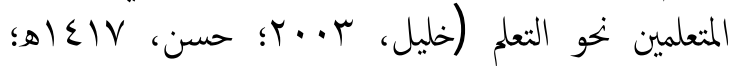

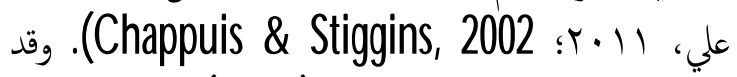

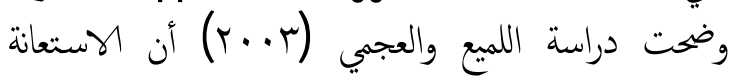

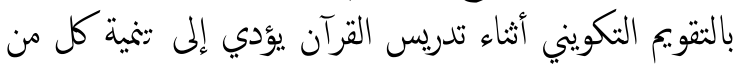

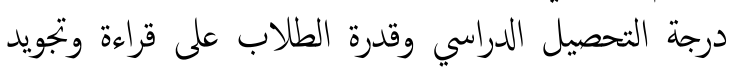

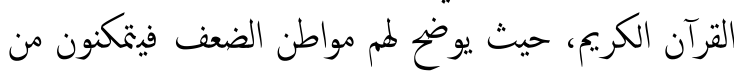

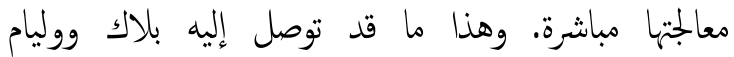

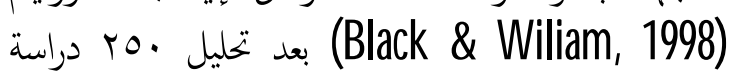

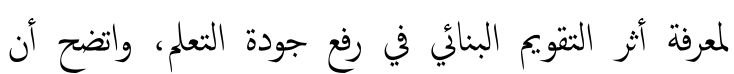

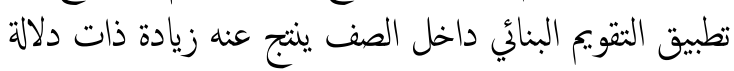

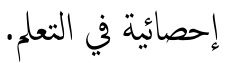
وقد يكون للدراسات التي لم تظهر فروقا ذات دلالة إحصائية

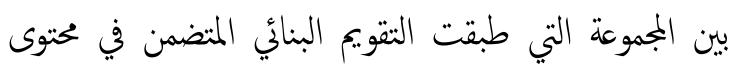

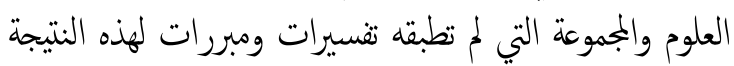


أ- هل توجد فروق ذات دلالة إحصائية بين آراء

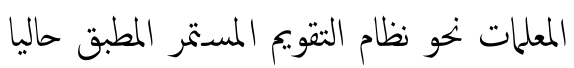

وآرائهن نحو نظام التقويم من أجل التعلم؟

ب- هل توجد فروق ذات دلالة إحصائية بين آراء

المشرفات نحو نظام التقويم المستمر المطبق حاليا

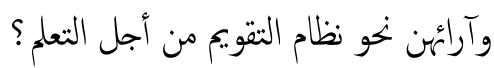

ج"- هل توجد فروق ذات دلالة إحصائية بين آراء

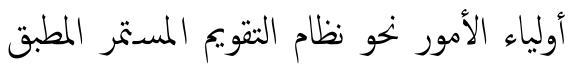

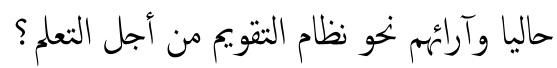

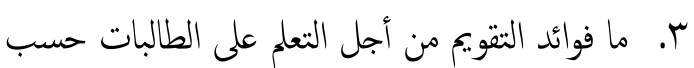

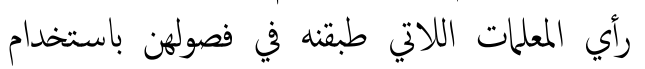

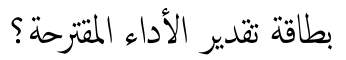

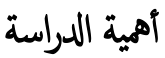

يعمل التقويم من أجل التعلم على تحديد الفجوة بين ما يعرفه

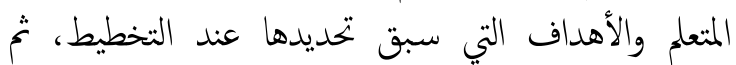

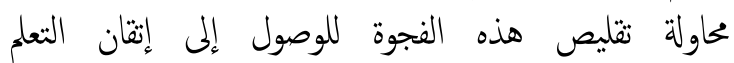
(Shirbagi \& Bahman, 2008) تعلم الطلاب، والفهم العميق للمعارف وربطها بحياتهم اليومية،

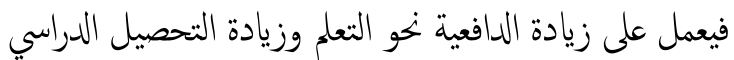

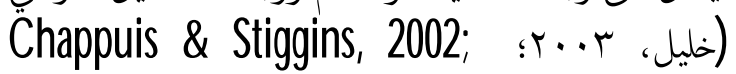
(Black \& Wiliams, 1998

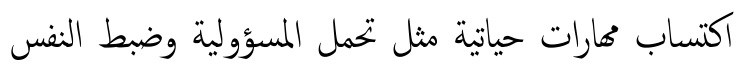

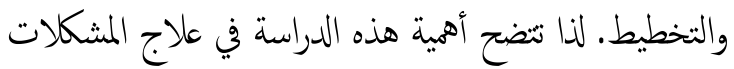

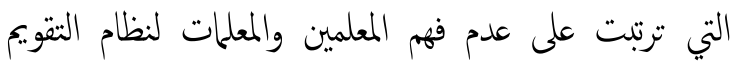

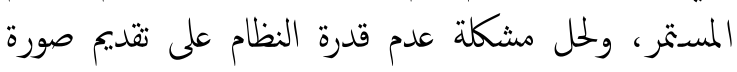

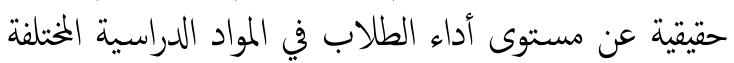

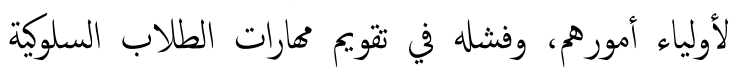

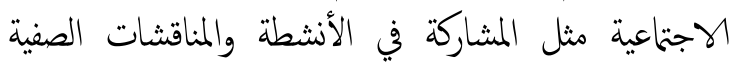

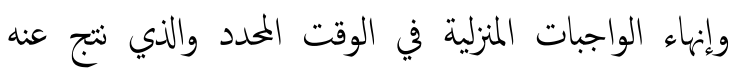
انخفاض مستوى التحصيلي للطلاب.

أهداف الدراسة

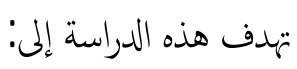

1. تعرف آراء المعلمات والمثرفات وأولياء الأمور بالتقويم

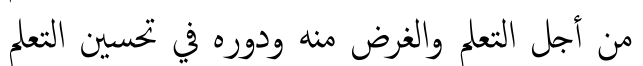
ودفعه إلى الأمام.
الطالبات لمعارف ومحارات العلوم للصف الرابع في ذلك العام

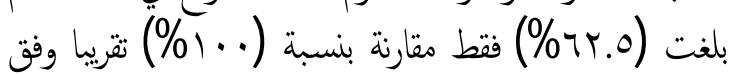
تقويم المعلمات.

في الوقت نفسه تثتتكي كثير من المعلمات من الخلل الذي

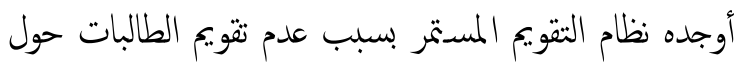

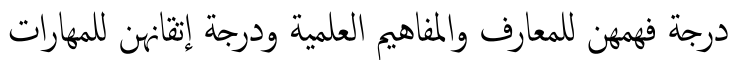

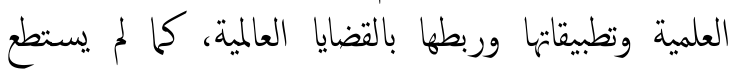

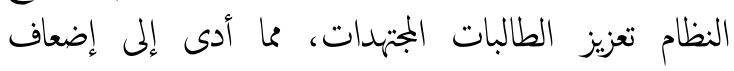
دافعيتهن نحو التعلم.

ومن السلبيات الكبيرة التي يعاني منها نظام التقويم المستمر

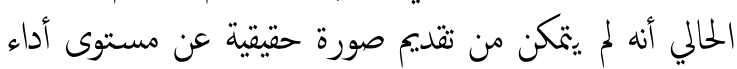

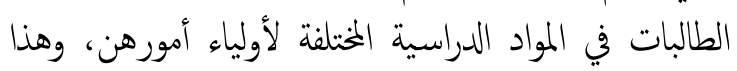

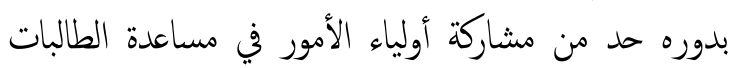

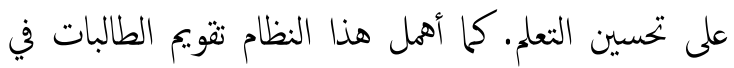

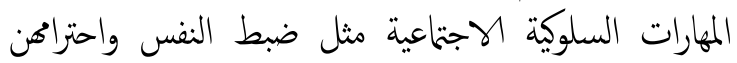

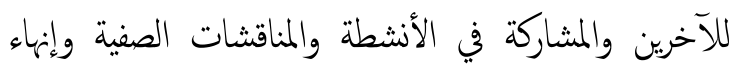

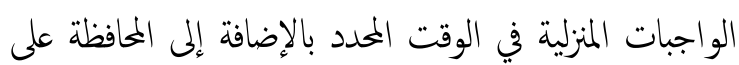

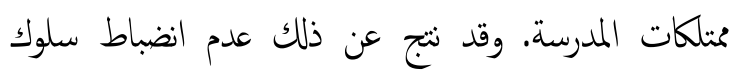

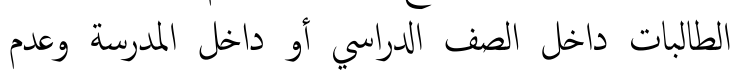

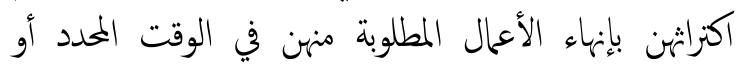

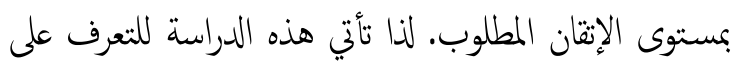

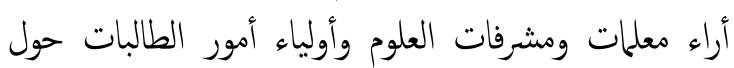

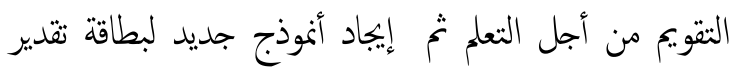
أداء الطالبة يساعد على تلافي القصور في البطاقة السابقة.

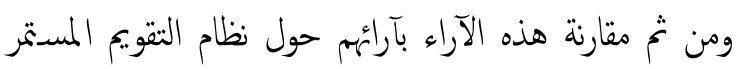
المطبق حاليا.

أسئة الدراسة

تسعى هذه الدراسة للإجابة عن الأسئلة التالية. 1. ما آراء معلمات ومشرفات العلوم التربويات وأولياء

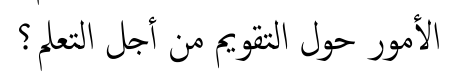
r. هل توجد فروق ذات دلالة إحصائية بين آراء العينة نهو نظام التقويم المستمر المطبق حاليا وآرائهم نهو نظام التقويم من أجل التعلم؟ ويتفرع عن هذا السؤال ثلاثة أسئلة' 
الرياض والبالغ عددهن لج مشرفة، وأولياء أمور طالبات

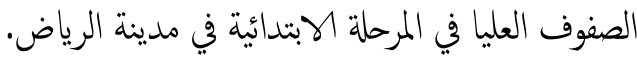

\section{وتكونت عينة الدراسة من جزأين}

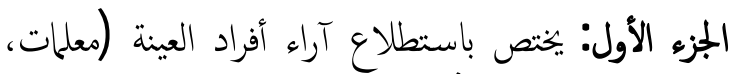

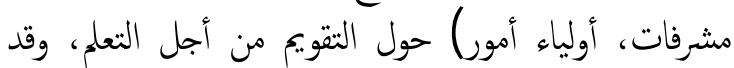

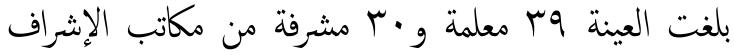

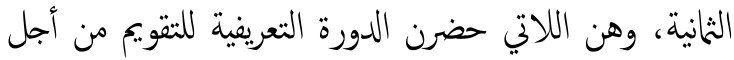

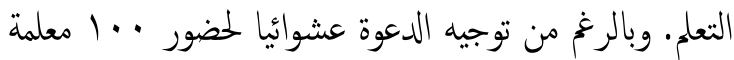

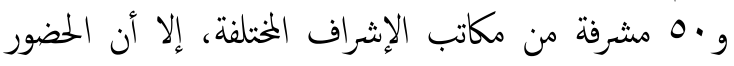

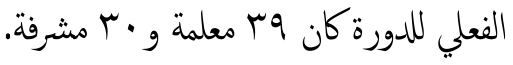

أما عينة أولياء الأمور فقد بلغت 9 و ولي أمر، وقد أختيرت

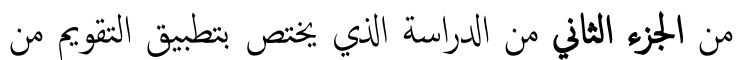

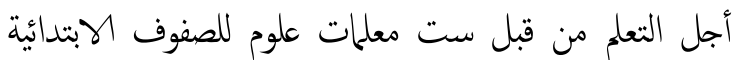

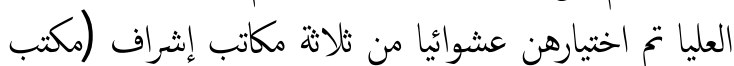

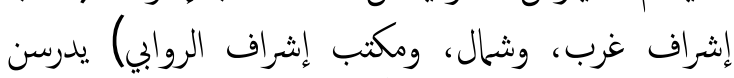
ع ro طالبة في 1 فصول (ع فصول للصف الرابع، فصلين

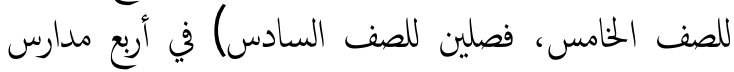

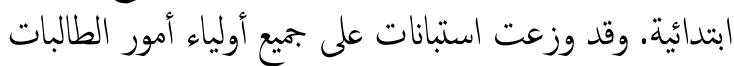

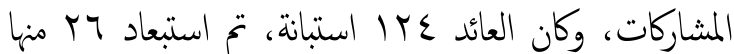
لعدم اكتمال بياناتها.

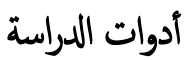

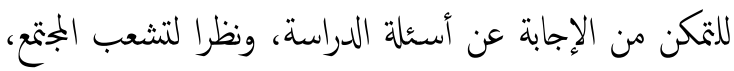

$$
\text { تم بناء الأدوات الآتية: }
$$

ا .الاستبانة: للإجابة عن أسئة الدراسة ما عدا السؤال

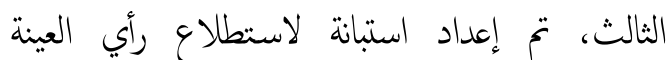

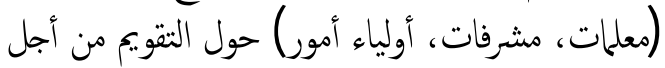

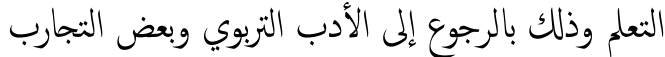

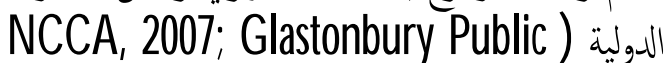
Schools, 2010; Progress Report Grades 45, 2012; Webster Groves School District Assessment Plan, 2011; Richland School District, 2012; Elementary StandardBased Report Card, 2003

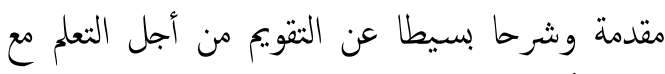

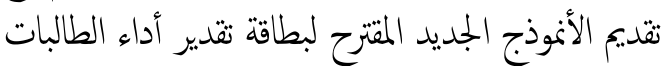

r. تقديم أنموذج جديد لبطاقة تقدير أداء الطالبات

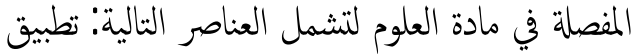

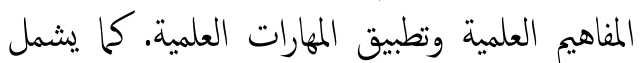

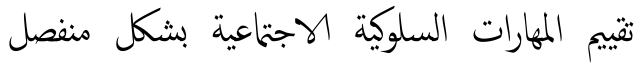
حتى يكتمل تقويم بوانب النمو المختلفة.

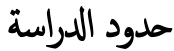

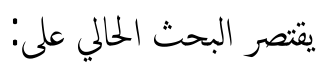

1. استطلاع آراء معلمات العلوم للصفوف العليا في المرحلة الابتدائية في المدارس الحكومية بمدينة الرياض، والمشرفات التربويات في مكاتب التربية والتعليم المختلفة حول التقويم من أجل التعلم، r. استطلاو آراء ست معلمات علوم للصفوف العليا في

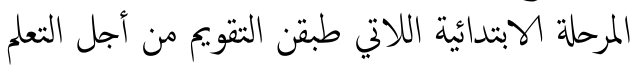
بأدواته المختلفة وبطاقة تقدير أداء الطالبات المقترحة الماته

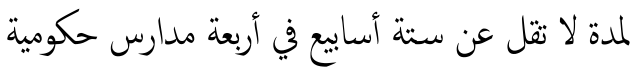

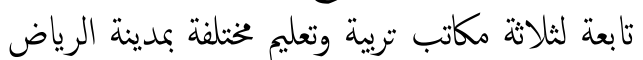
حول فوائده على الطالبات. كما تم استطلاع ماع أولياء أمور الطالبات في هذه المدارس حول التقويم من

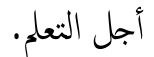
r. طبقت هذه الدراسة في العام الدراسي ه

\section{الطريقة والإجراءات}

\section{منهج الدراسة} اتبعت الدراسة المنهج الوصفي للنعرف على' آراء أفراد العينة

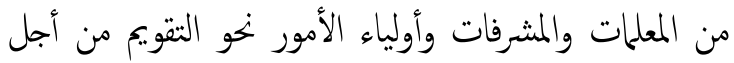

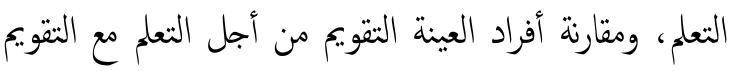
المستمر المطبق في المدارس.

\section{مجتع وعينة الدراسة}

تكون مجتمع الدراسة من: جميع معلمات العلوم للصفوف العليا

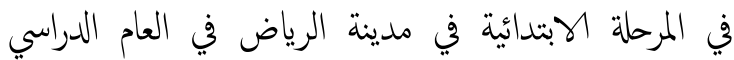

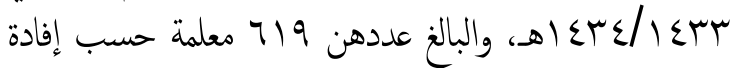

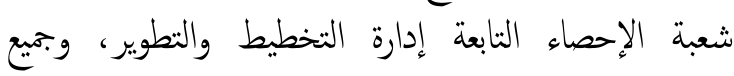

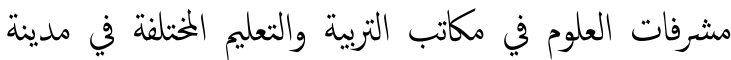




\section{O م تحفظ على متلكات المدرسة}

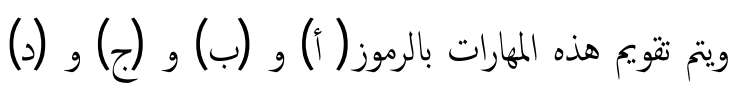

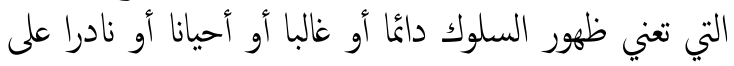

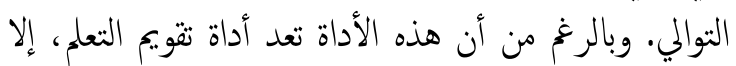

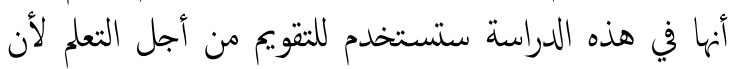

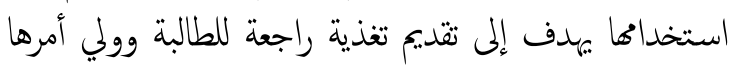

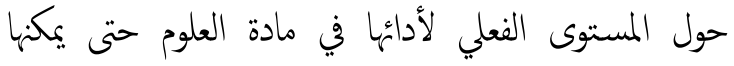
تحسين وتطوير جوانب الضعف، وتعزيز جوانب القوة. صدق الأدوات: للتحقق من الصدق الظاهري لأدوات

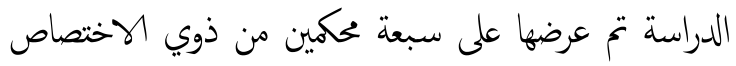

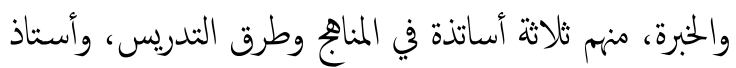

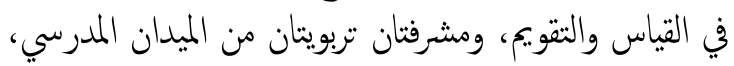

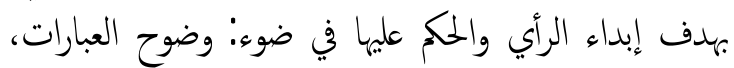
ومناسبتها لتحقيق أهداف الدراسة، وسلامة صياغتها اللغوية الدية.

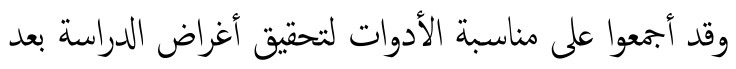

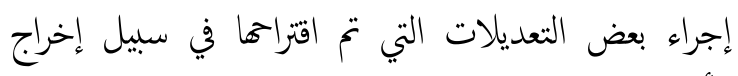
الأدوات في صورتها النهائية.

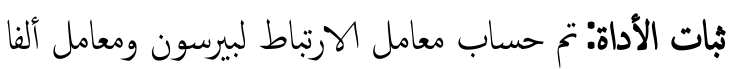
كرونباخ لحساب ثبات الأساق الداخلي لعبارات الأداة.

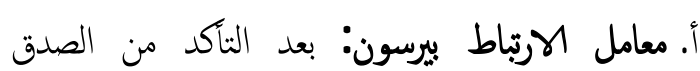
الظاهري لأداة الدراسة قامت الباحثة بتطبيقها على عينة

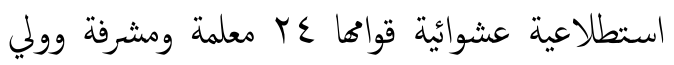

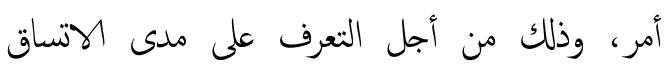

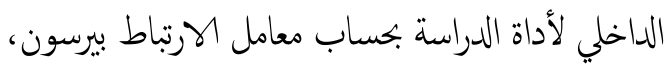

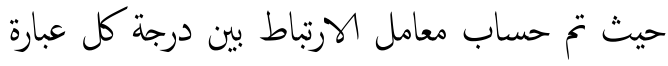

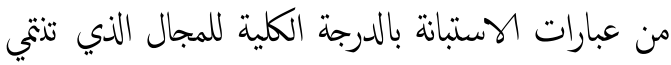

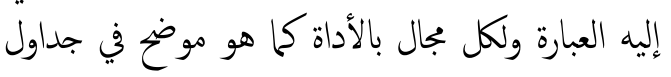
ا
والبيانات الأولية للمعلمة أو المشرفة أو ولي الأمر،

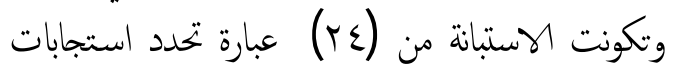

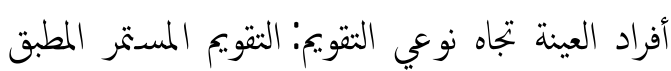

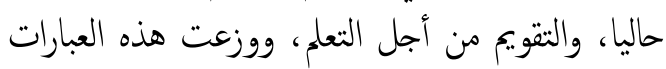

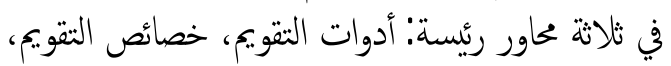

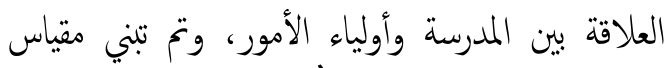

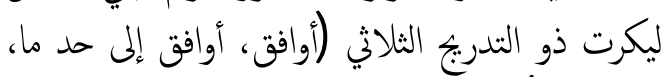

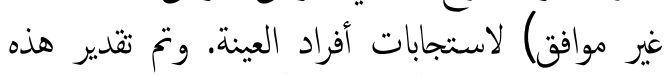

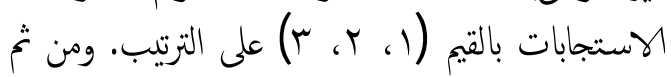
حساب التكرارات والنسب المئوية.

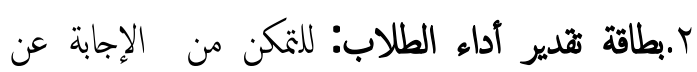

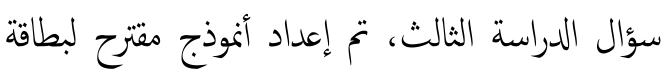

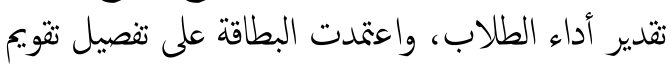

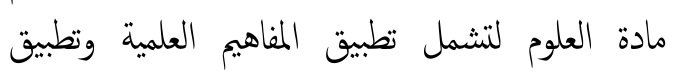

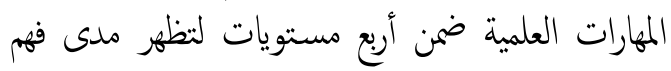

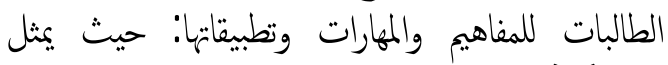

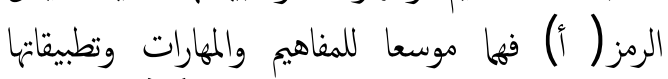

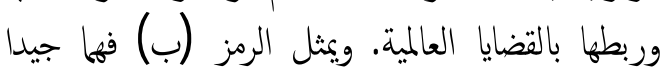

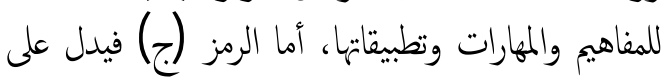

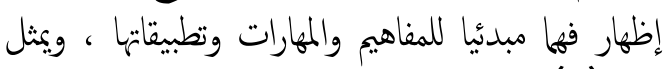

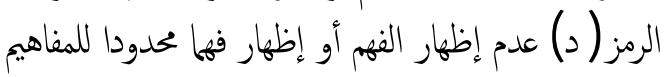
والمهارات وتطبيقاتها.

أما المهارات السلوكية الاجتاعية فتم تقويها من خلال المهارات

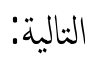

$$
\begin{aligned}
& \text { O } \\
& \text { O تشارك في الأنشطة والمناقشات الصفية } \\
& \text { O } \\
& \text { O } \\
& \text { O } \\
& \text { O } \\
& \text { O } \\
& \text { O } 0 \\
& \text { O } \\
& \text { O متافظ على متملكاتها الشخصية }
\end{aligned}
$$




\section{جدول 1}

معاملات ارتباط بيرسون لعبارات المحور الأول (أدوات التقويم) بالدرجة الكلية للمحور

\begin{tabular}{|c|c|c|}
\hline 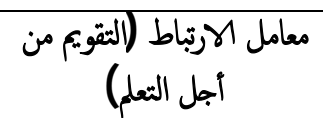 & 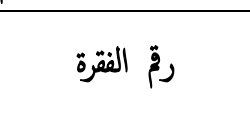 & معامل الارتباط (لتقويم المستر المطبق) \\
\hline$* *, V 741$ & 1 & **.,099 \\
\hline **., VTr & $r$ & **, OVT \\
\hline **, VOr & $r$ & **.,010 \\
\hline **., VVr & $\varepsilon$ & 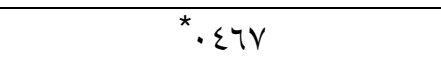 \\
\hline$*, 009$ & 0 & $*^{*}, \pi(T)$ \\
\hline **., $V \leqslant V$ & 7 & **, \\
\hline *T.,OK & V & $*^{*}, V_{Y}$. \\
\hline$*_{\cdot, \varepsilon \wedge \vee}$ & $\wedge$ & $* * \cdot, \Lambda \cdot r$ \\
\hline **.,09 & 9 & **, $V I V$ \\
\hline$*_{\cdot,} \leq 7 V$ & 1. & **.,790 \\
\hline$* * ., 0 \wedge \mathrm{V}$ & ارتباط المحور بالدرجة & **., $\wedge \varepsilon \varepsilon$ \\
\hline \multicolumn{3}{|c|}{ 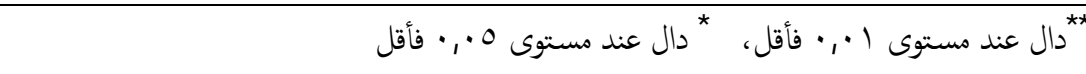 } \\
\hline \multicolumn{3}{|c|}{ معاملات ارتباط بيرسون لعبارات المجال الثاني (خصائص الثقويم) بالدرجة الكلية للمحور } \\
\hline $\begin{array}{c}\text { معامل الارتباط (التقويم من التعلم) } \\
\text { أتجل }\end{array}$ & رق الفقرة & معامل الارتباط (التقويم المستمر المطبق) \\
\hline **,VAY & 11 & **.,$\wedge Y$. \\
\hline$* *, V \vee \neg$ & IT & ${ }^{*} \cdot 7.9$ \\
\hline **.,oro & $\pi$ & $*^{*}, 011$ \\
\hline$* * \cdot, \wedge \varepsilon \varepsilon$ & $1 \varepsilon$ & ${ }^{* *} \cdot \wedge 79$ \\
\hline$*^{*}, \vee \vee \neg$. & 10 & * * r, \\
\hline$* * ., 9.9$ & 17 & $* *, \wedge \ldots$ \\
\hline$* * ., 9 \cdot 7$ & IV & $*^{*}$, vq. \\
\hline$* *, \wedge \vee \wedge$ & 11 & $* *, \wedge \vee\urcorner$ \\
\hline **., VAᄉ & 19 & 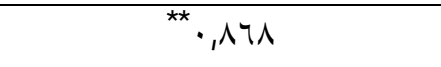 \\
\hline **., 940 & $r$. & ${ }^{* *},, \wedge \wedge \wedge$ \\
\hline **., q 9 & ارتباط المحور بالدرجة & **.,90r \\
\hline
\end{tabular}




\section{جدول r}

معاملات ارتباط بيرسون المحور الثالث (العلاقة بين المدرسة وأولياء الأمور بالدرجة الكلية للمحور)

\begin{tabular}{|c|c|c|}
\hline معامل الارتباط (التقويم من أجل التعلم) & رقّ الفقرة & معامل الرتباط (لثقويم المستمر المطبق) \\
\hline$* * ., 991$ & r) & $* * ., 910$ \\
\hline$* * ., 991$ & TY & **., $\wedge 97$ \\
\hline **.,991 & Tr & **., qur \\
\hline **., $9 \wedge \vee$ & $T \varepsilon$ & 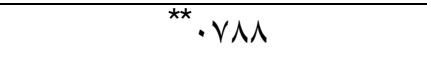 \\
\hline$* *,, \Lambda 0 \leqslant$ & ارتباط المحور بالدر & **. , $\wedge \vee \neg$ \\
\hline
\end{tabular}

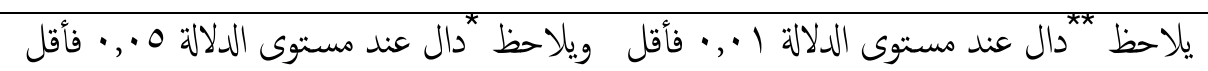

جدول ع

حساب معامل ألفاكونباخ لثبات الاتساق الداخلي للاستبانة

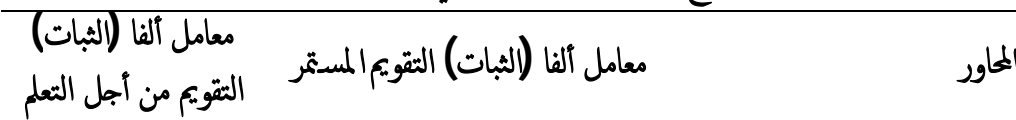

\begin{tabular}{|c|c|c|c|}
\hline$\cdot, \Lambda Y \Lambda$ & $\cdot$,AYT & أدوات التقويم & المحور الأول \\
\hline$\cdot, 9 \mathrm{rv}$ & $\cdot, 9 T V$ & خصائص التقويم & المحور الثاني \\
\hline$\cdot, 99 \mathrm{~V}$ & $\cdot, 9 \cdot \varepsilon$ & العلاقة بين المدرسة وأولياء الأمور & المحور الثالث \\
\hline$\cdot, 9 \leqslant \varepsilon$ & $\cdot, 97 \pi$ & & الأداة كاملة \\
\hline
\end{tabular}

الثالث وللتعرف على فوائد تكامل التقويم مـن أجل التعلم في

تدريس العلوم وللتعرف على الصعوبات التي وابتهنهن.

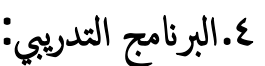

هدف البرنامج التدريبي إلى تعريف معلمات العلوم والمشرفات

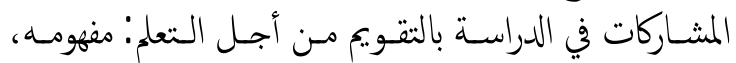

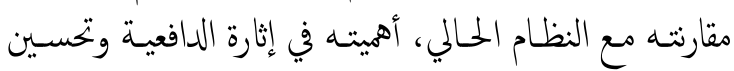

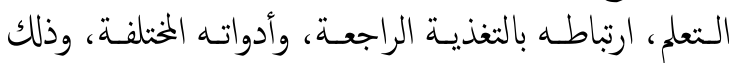

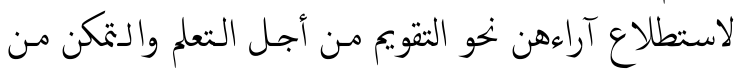

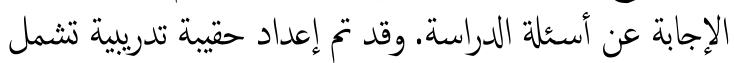

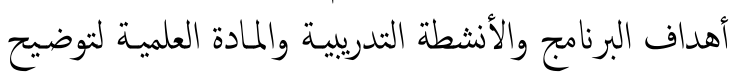

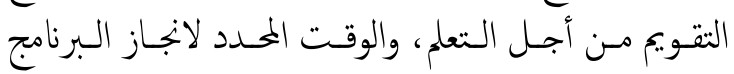

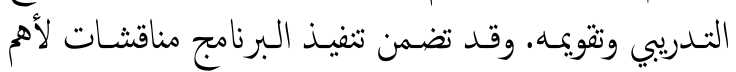

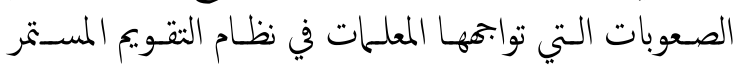
المطبق حاليا في المدارس، ومتترحاتهن لعلاجه، كمنطلق لتقديم

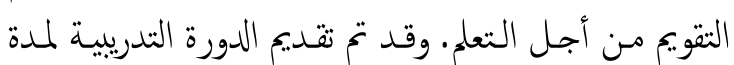

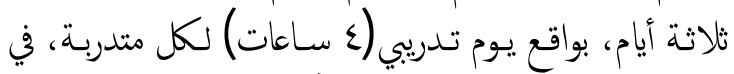

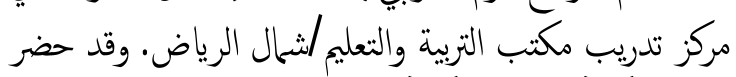

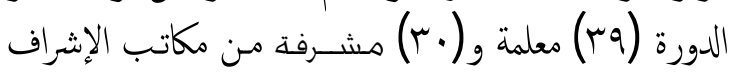

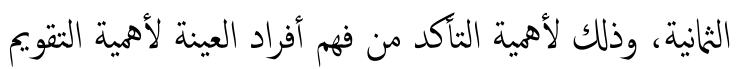

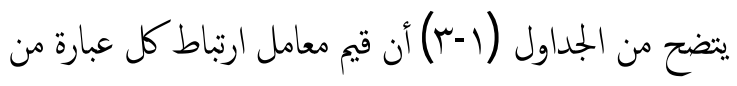

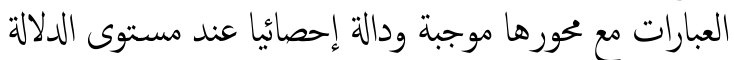

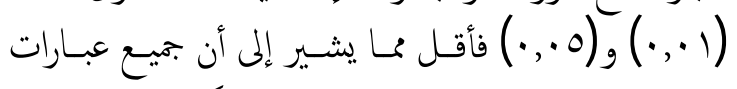

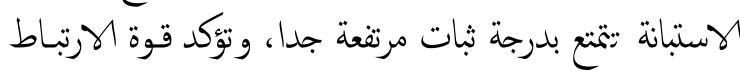

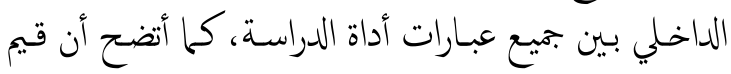

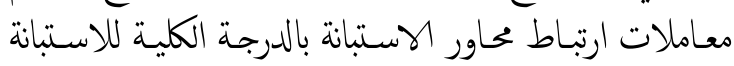

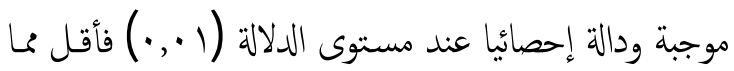

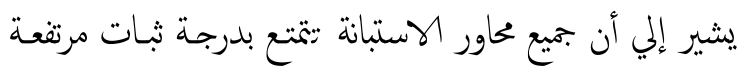

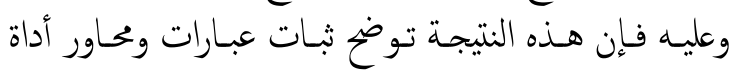
الدراسة وصلاحيتها للتطبيق الميداني.

\section{بי معامل ألفاكرونباخ'}

يتضح من جدول (ع) أن قيم معامل ألفاكرونباخ تتراوح بين

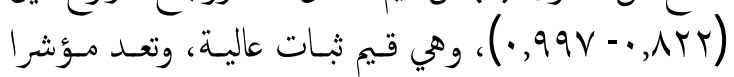

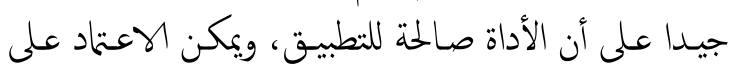
نتائجها.

\section{r. المقابلة الشخصية'}

تم إجراء مقابلات شخصية مع المعلمات اللاتي طبقن بطاقة تقدير الأداء في فصولهن وذلك بهدف الإجابة عن السؤال 
آراء العينـة نحو نظـام التقويم المسـتمر المطبق حاليـا

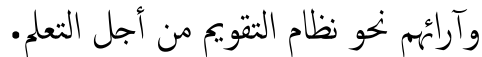

\section{نتائُ الدراسة ومناقثتهها}

للإجابة عن السؤال الأول: ما رأي أفراد عينة الدراسة حول

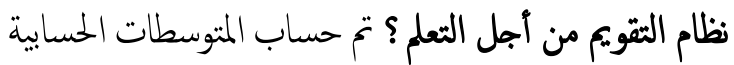

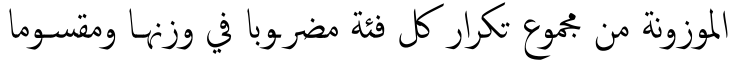

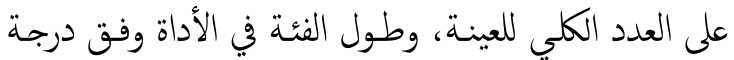

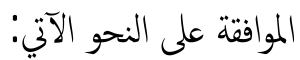

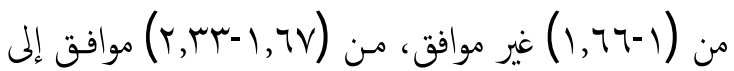

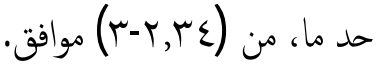
المحسور الأول' أدوات التقويم' يـوضح جـدول ه المتوسطات

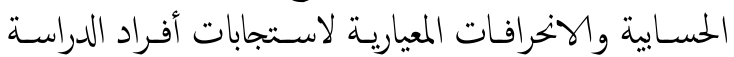

$$
\text { حول المحور الأول، أدوات التقويم. }
$$

يتضح من جدول ه أن المتوسط الحسابي العام لدرجة أهمية

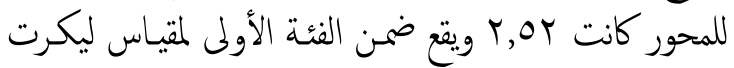

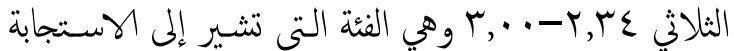

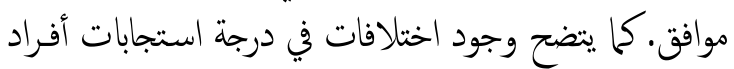

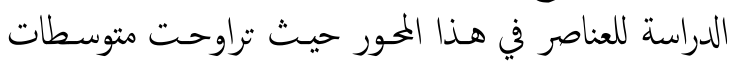

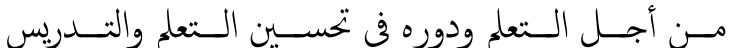

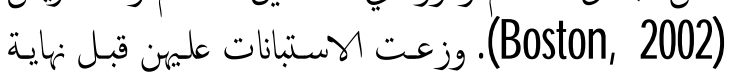

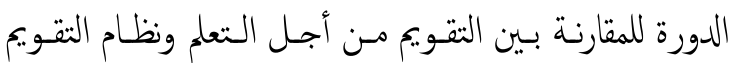

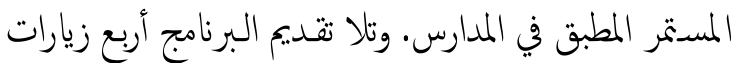

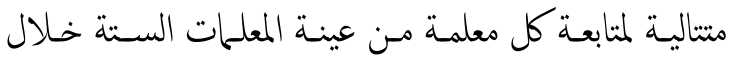

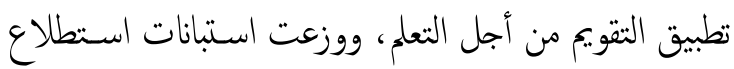
آراء أولياء الأمور بعد ستة أسابيع من التطبيق.

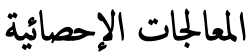

تم استخدام الأساليب الإحصائية التالية: I ـ معامل ألفاكرونباخ (Alpha Cronbach) ومعامـل بيرسون (Pearson) للاتساق الداخلي لحساب ثبات

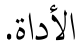
r. المتوسط الحسابي والانحرافات المعيارية والنسب المئوية

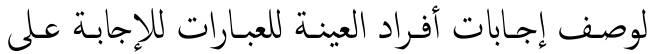

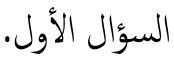
r. اختبار - ت للعينات المترابطة للإجابة عن السؤال الثاني للكثف عن وجود فروق ذات دلالة إحصائية بين

\section{جدول}

المتوسطات الحسابية والانحرافات المعيارية لاستجابات أفراد الدراسة حول أدوات التقويم

\begin{tabular}{|c|c|c|c|c|}
\hline الانحراف المعياري & الوسط الحسابي & الترتب & العبارة & الرق \\
\hline$\cdot, 79$ & T,Tr & 7 & تستخدم أدوات تقويم متنوعة لقياس المعارف بأكزر من طريقة للتأكد من صحة القياس. & 1 \\
\hline$\cdot$, TV & $r, 7)$ & $\checkmark$ & تستخدم أدوات تقويم متنوعة لقياس المهارات العلمية. & r \\
\hline$\cdot$, AT & $r_{1} \cdot \cdot$ & 9 & الأسئلة الشفوية هي الأكثر استخداما لقياس المعرفة العلمية. & r \\
\hline$\cdot, \wedge 9$ & 1,94 & $1 \cdot$ & يقاس إتقان المعرفة بعد حفظها بذكرها أمام المعلمة. & $\varepsilon$ \\
\hline$\cdot, 7$. & $r, V \varepsilon$ & 1 & تطبق اختبارات تحريرية دورية لقياس فهم الطالبات. & 0 \\
\hline$\cdot, 71$ & r, Y I & r & تطبق اختبارات شاملة للوحدة للتحقق من فهم الطالبات. & 7 \\
\hline$\cdot, 09$ & $r, \top \Lambda$ & 0 & على تطبيقها في الحياة، & V \\
\hline$\cdot, 07$ & $r, 79$ & $\varepsilon$ & يساعد تقرير تقدير أداء الطالبات في تحديد مدى تمكن الطالبة من المهارات العلمية. & $\wedge$ \\
\hline$\cdot, 01$ & $r, r)$ & r & يساعد تقرير تقدير أداء الطالبات في توضيح تقدم تعلم الطالبة. & 9 \\
\hline$\cdot, 1)$ & r,or & $\wedge$ & يساعد تقرير تقدير أداء الطالبات في توضيح تقدم الطالبة في المهارات السلوكية & 1. \\
\hline$\cdot, 77$ & r,Or & & 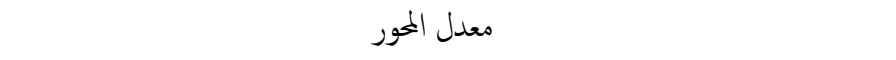 & \\
\hline
\end{tabular}


O جاء البند الذي تمثله الفقرة رقٌ م وهي "يساعد تقرير

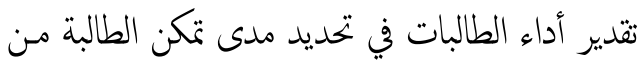

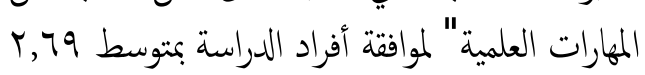

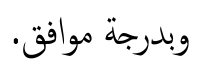

ومما سـبق يتضح تفضيل النموذج المقترح لبطاقة تقدير أداء

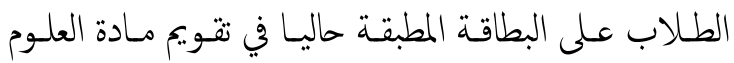

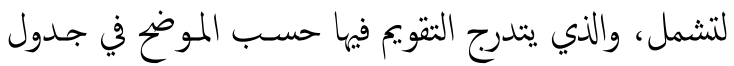
ا ـ وبهدف ذلك إلى تقديم تغذية راجعة للطالبة وولي أمرها

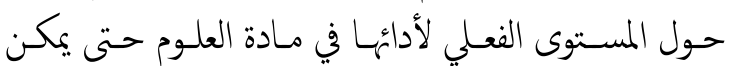
تحسينه وتطويره، وتعزيز جوانب القوة فيهن. O حصـلت الفتـرة رقز بـ وهي "الأسـئلة الشـفوية هي

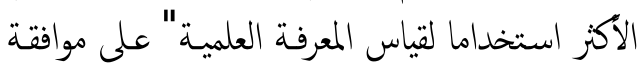

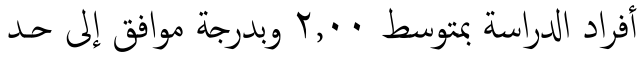

O حصلت الفقرة رقّ ع وهي "يقاس إنقان المعرفة بعد حفظها بذكرها أمام المعلمة" على موافقة أفراد المقاد المراسة بمتوسط سو, 1 وبدرجة موافق إلى حد ما. رغز أن هذه البنود قد حققت درجات منخفضة نسبيا، إلا أن

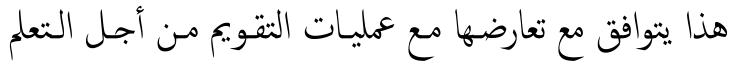

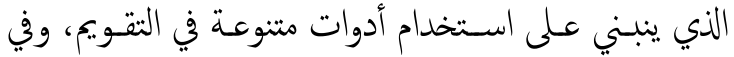

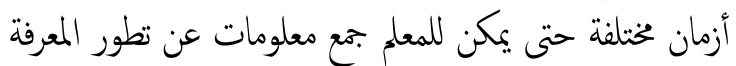

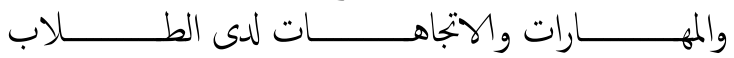

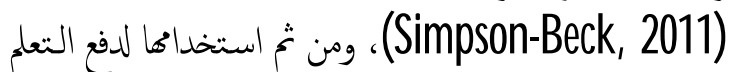

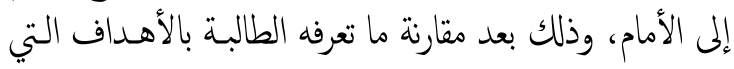

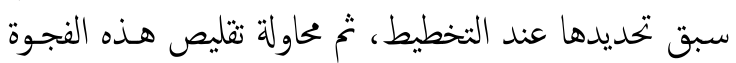

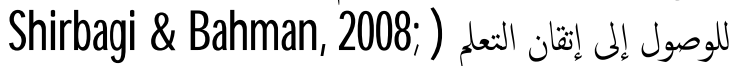
. Black, et al., 2004; Wiliam, 2011

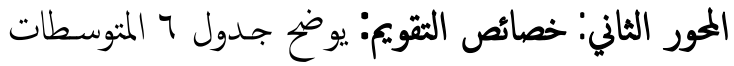

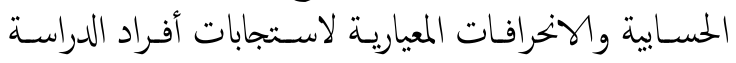

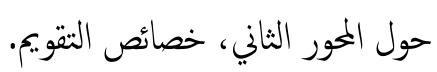
من خلال جدول 7 يتضح أن المتوسط الحسابي العام لدرجة المَّة

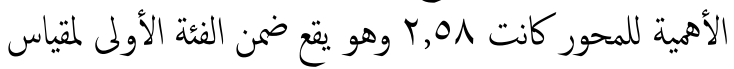

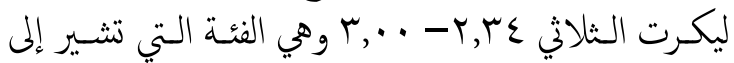

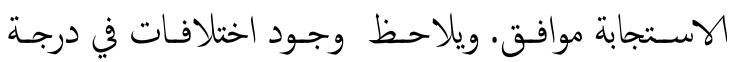

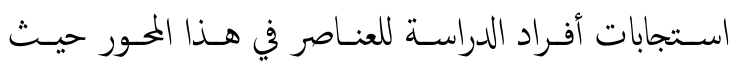

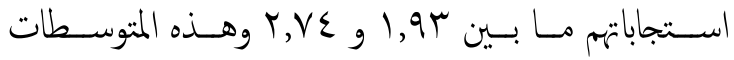

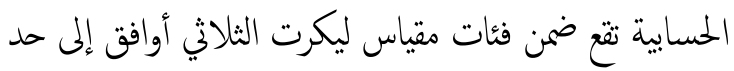

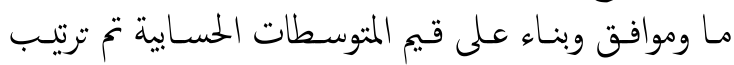

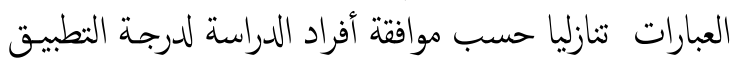

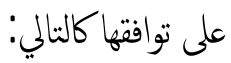

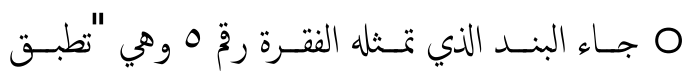

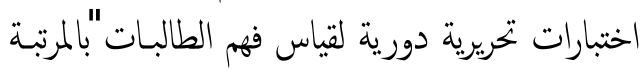

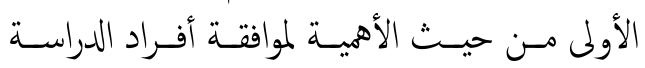
بمتوسط Y Y,V و وبدرجة موافق.

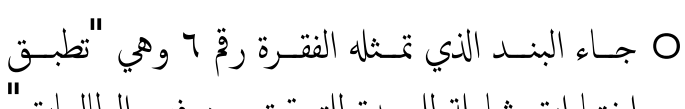
اختبارات شاملة للوحدة للتحقق مـن فهم الطالبات المقات بالمرتبة الثانية من حيث الأهية لموافقة أفراد الدراسة فلمة الماتحة

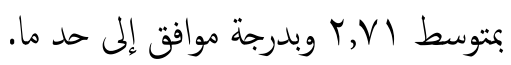

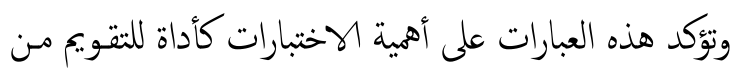

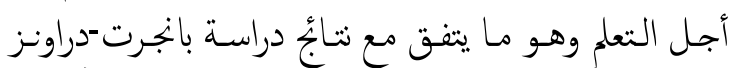
وزماؤه (Bangart-drowns et al., 1991 التي

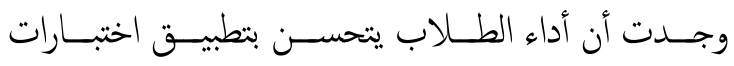

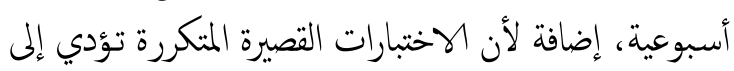

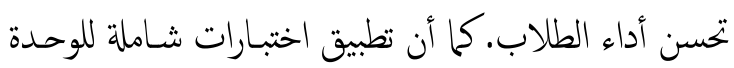

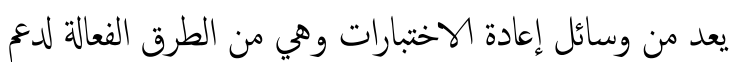

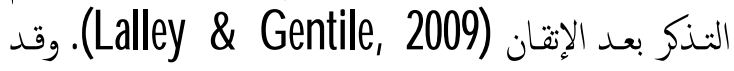

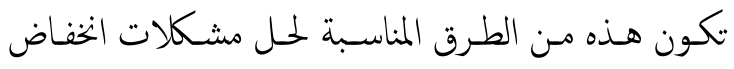

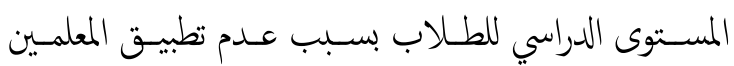

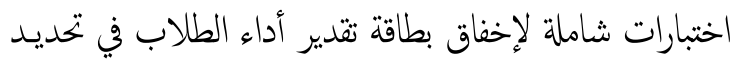
درجة فهمهم للمعارف والمفاهيم العلمية ودرجة إتقانهم للمهارات

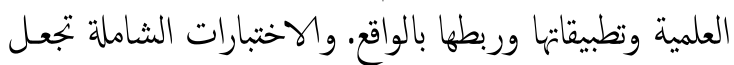

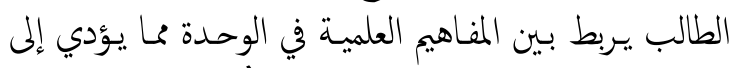

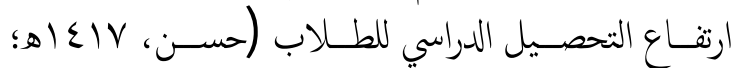
Wiliam, et. al., 2004; Volante \& Beckette, .2011 O جاء البند الذي تمثله الفقرة رقز V وهي "يسـاعد تقرير

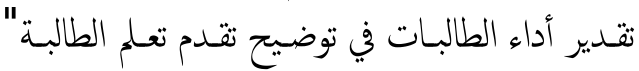

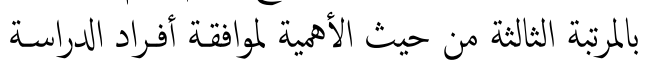

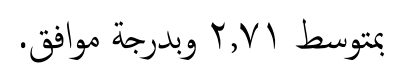




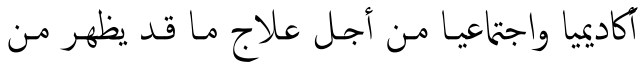

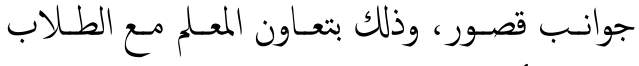
وأولياء الأمور والإدارة المدرسية.

O جاءت الفقرة رقّ 10 وهي توضيح نقاط الضعف عند الطماند الطالبات "بالمرتبة الثانية من حيث الأهمية لموافقة أفراد

الدراسة بمتوسط ب, T0 وبدرجة موافق إلى حد ما.

O جاءت الفقرة رقٌ ع ا وهي "لوضيح نقاط القوة عند

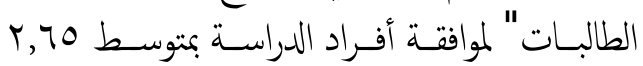

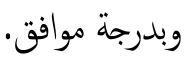

م كما جاءت الفقرة رقُّ 11 وهي "القديم تغذية راجعة

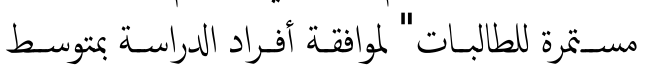

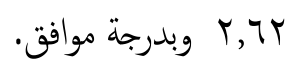

وما سبق يوضح أهيـة النغذية الراجعة التي تعمل على

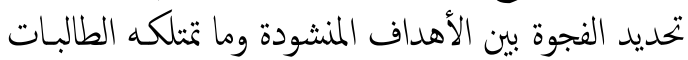

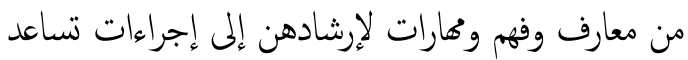

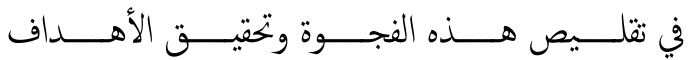
كا تساعد التغذية الراجعة الطالبات (Wiliam, 2011) على اكتساب وتطوير مهارات التقويم الذاتي مـ خـ خلال

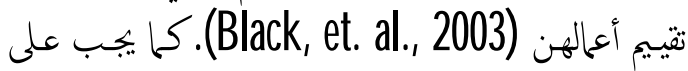
المعلمة أن تقدم تغذية راجعة مفصلة بقدر كاف ومناسبة

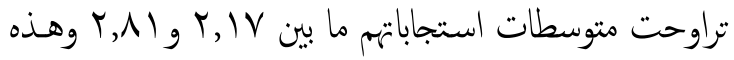

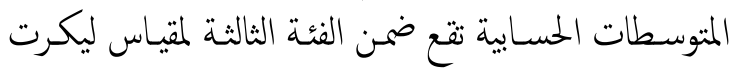

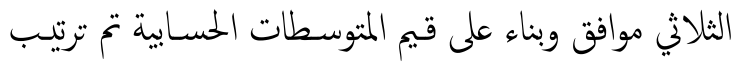

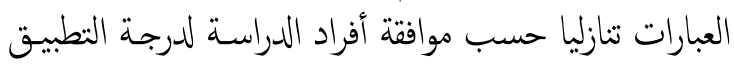

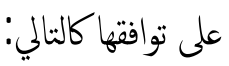
O جاءت الفقرة رقٌ 17 وهي "حث الطالبات على حل

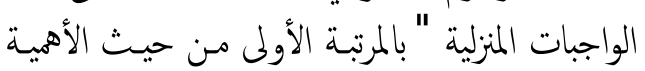

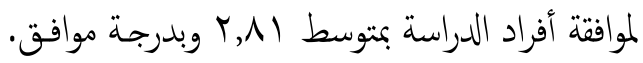

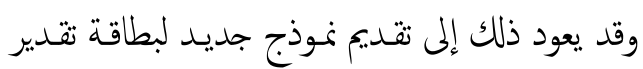

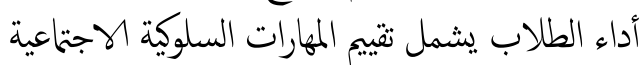

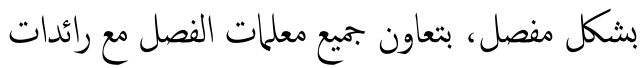

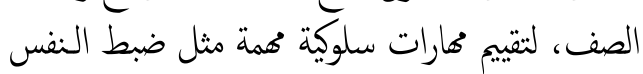

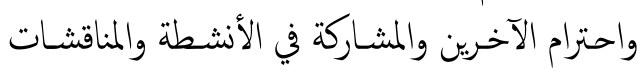

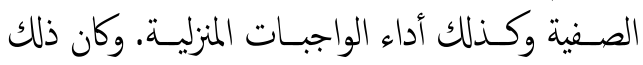

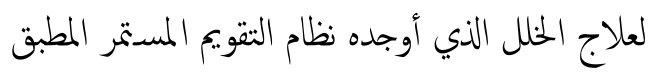

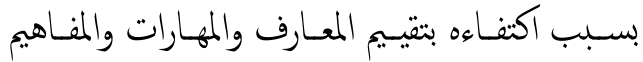

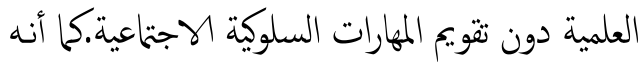

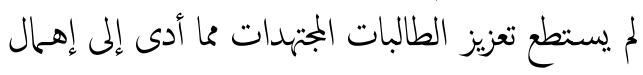

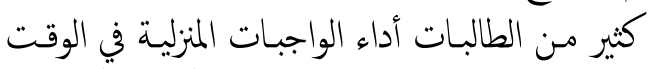

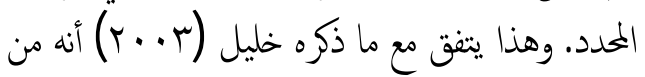

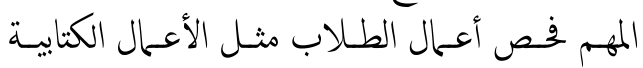

جدول 1 والواجبات المنزلية وملفات الانجاز التي تصف أدائهم

\begin{tabular}{|c|c|c|c|c|}
\hline الانحراف المعياري & الوسط الحسابي & الترتب & 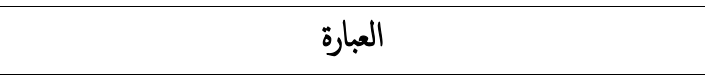 & الرق \\
\hline$\cdot, 70$ & $r, T r$ & 0 & تقديم تخذية راجعة مستمرة للطالبات. & 11 \\
\hline$\cdot, 71$ & $r, 09$ & 7 & تجميع مستمر للشواهد على تقدم الطالبة. & ir \\
\hline$\cdot, 19$ & $r_{1} I V$ & $1 \cdot$ & تتييم المهارة مباشرة بعد الدرس أو الفصل ولا يتم مراجعتها بعد ذلك. & ir \\
\hline 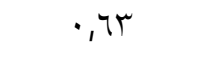 & $r, 70$ & $\varepsilon$ & توضيح نقاط القوة عند الطالبات. & $1 \varepsilon$ \\
\hline$\cdot, 71$ & $r, 70$ & r & توضيح نقاط الضعف عند الطالبات. & 10 \\
\hline$\cdot, 00$ & $r, \wedge 1$ & 1 & حث الطالبات على حل الواجبات المنزلية. & 17 \\
\hline$\cdot, 7$ & $r, 70$ & r & تقرير تقدير أداء الطالبات يحدد مدى إتقان المعارف والمهارات. & iv \\
\hline$\cdot, v r$ & $r, 09$ & $\checkmark$ & نظام التقويم يساعد على ترابط المادة العلمية لدى الطالبات. & 11 \\
\hline$\cdot, v V$ & $r, \varepsilon \uparrow$ & 9 & يراعي نظام التقويم الفروق الفردية بين الطالبات. & 19 \\
\hline$\cdot, v 7$ & r,OV & $\wedge$ & يحث نظام التقويم الطالبات على الجدية وتحمل مسؤولية التعلم. & $r \cdot$ \\
\hline$\cdot, 79$ & r,OA & & 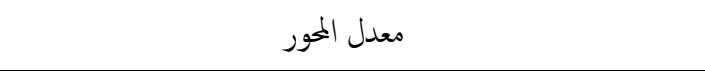 & \\
\hline
\end{tabular}

المتوسطات الحسابية والانحرافات المعيارية لاستجابات أفراد الدراسة حولi خصائص الثقويم 
الأهمية لموافقة أفراد الدراسة بمتوسط T,77 وبدرجة

موافقن.

O جاءت الفقرة رقً r و وهي "يساعد على تعريف أولياء

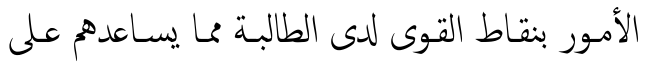
تعزيزها" بالمرتبة الثانية مكرر من حيث الأهمية لموافقة الفحة

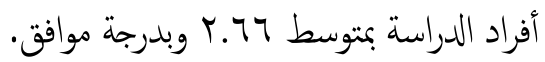
ولعل موافقة أفراد العينة بدرجة عالية في أن أدوات التقويم

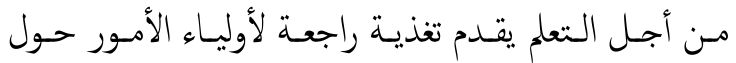

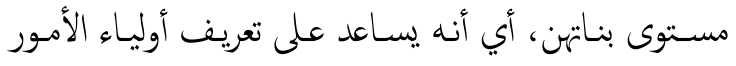

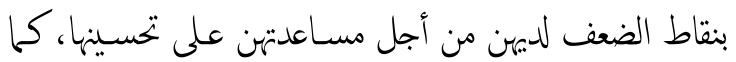

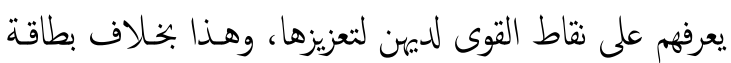

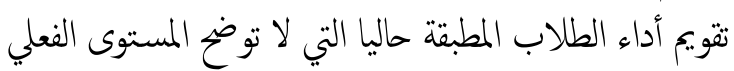

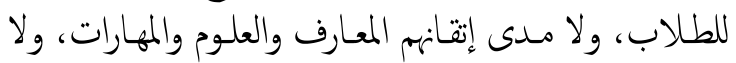

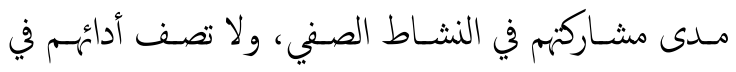

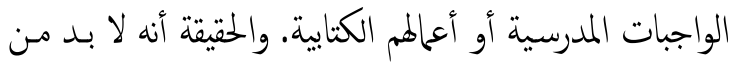

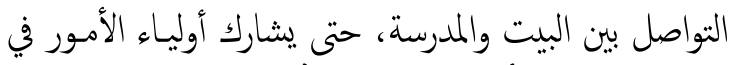
عملية تعلم أبنائهم (NCCA, 2007).

للإجابة عن السؤال الثاني: هـل توجد فروق ذات دلالة إحصائية بين آراء العينة نحو نظام التقويم المستمر المطبق حاليا

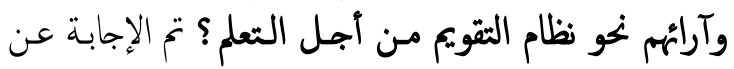

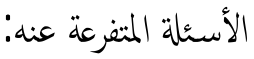

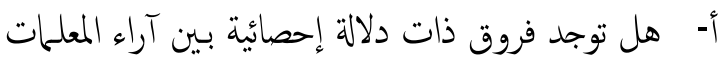

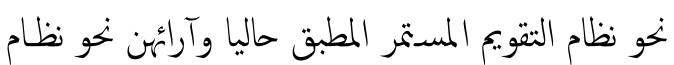

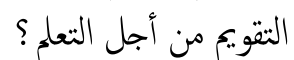
ب- هل توجد فروق ذات دلالة إحصائية بين آراء المشرفات

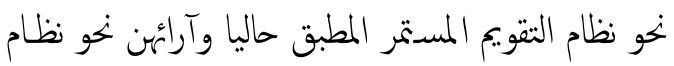

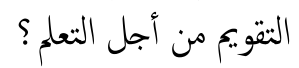

لفهم الطالبات، وبأسرع وقت، وأن تكون مستمرة، ومرتبطة

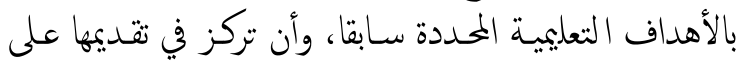

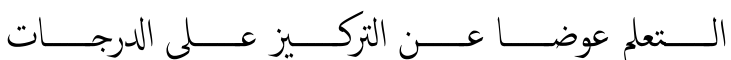

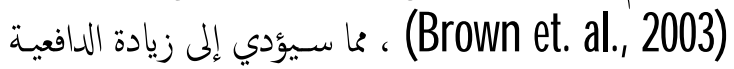

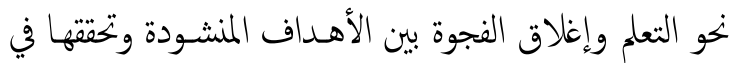

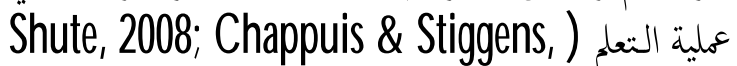
.(2002; Elshout-M ohr, 1994

المحور الثالث: العلاقة بين المدرسة وأوليـاء الأمـورن يوضح

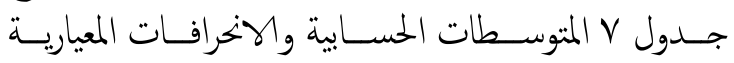

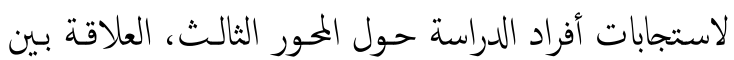
المدرسة وأولياء الأمور. من خلال جدول V يتضح أن المتوسط الحسابي العام لدرجة

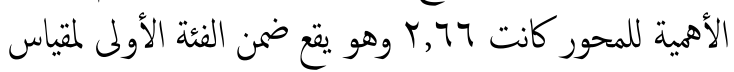

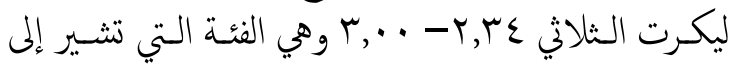

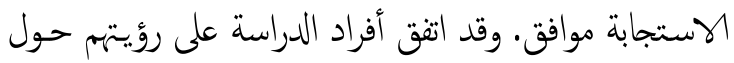

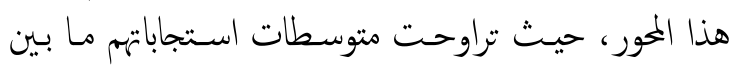

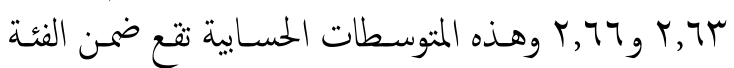

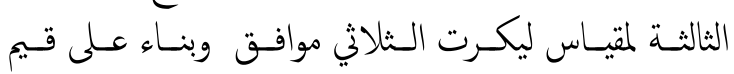

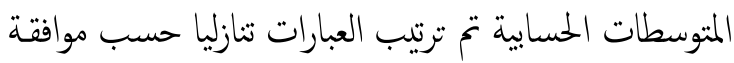
أفراد الدراسة لدرجة التطبيق على توافقها كالتالي: O جاءت الفقرة رقّ بr وهي "يساعد على تعريف أولياء

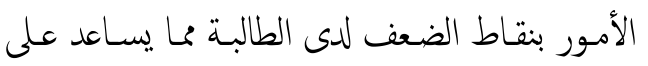

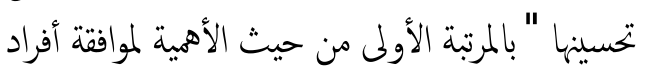

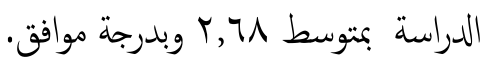
O جاءت الفقرة رقً اب وهي "يقدم تغذية راجعة لأولياء

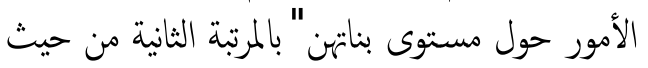

\section{جدول V}

المتوسطات الحسايية والانحرافات المعيارية لاستجابات أفراد الدراسة للمحور الثالث: العلاقة بين المدرسة وأولياء الأمور

\begin{tabular}{|c|c|c|c|c|}
\hline المعياري & الحسابي & 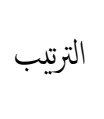 & 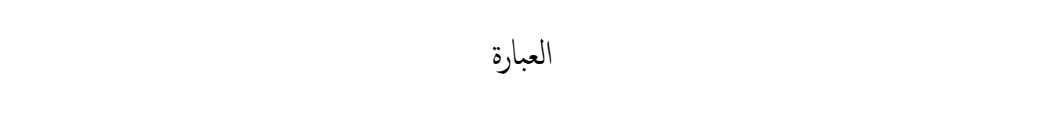 & 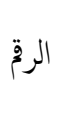 \\
\hline$\cdot, T V$ & $r, 77$ & r & يقدم تغذية راجعة لأولياء الأمور حول مستوى بناتهن. & r) \\
\hline$\cdot, \mathrm{TV}$ & $r, 77$ & r & يساعد على تعريف أولياء الأمور بنقاط القوة لدى الطالبة مما يساعدهم على تعزيزها. & rt \\
\hline$\cdot, T \varepsilon$ & $r, r u$ & 1 & يساعد على تعريف أولياء الأمور بنقاط الضعف لدى الطالبة ما يساعد على تحسينها. & r \\
\hline$\cdot, 7 \Lambda$ & $r, \pi$ & $\varepsilon$ & يتطلب اجتاعات فردية بين المعلمة وأولياء الأمور من أجل توضيح الصعوبات التي تواجهها الطالبات. & $r \varepsilon$ \\
\hline$\cdot, \mathrm{TV}$ & $r, 47$ & & معدل المور & \\
\hline
\end{tabular}


أولياء الأمور حول نظام المعلمات التربويات والمعلمات الغير

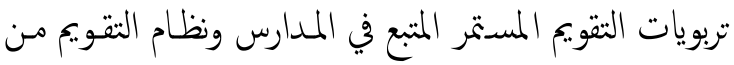

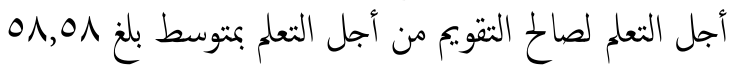

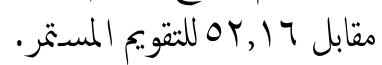

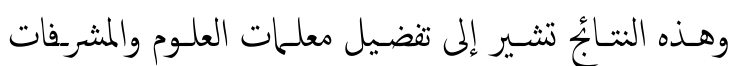

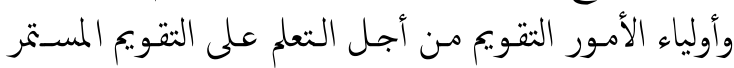

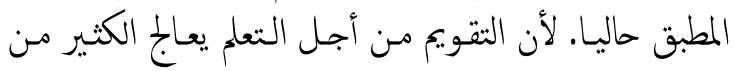

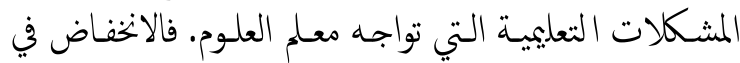

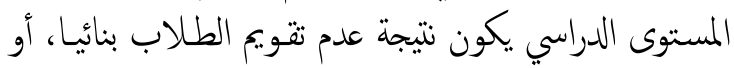

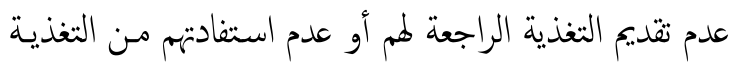

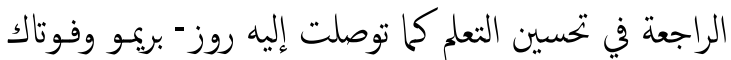

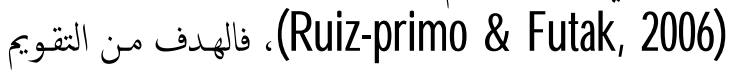

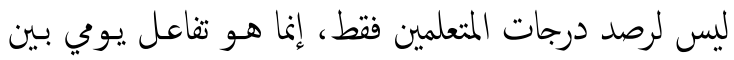

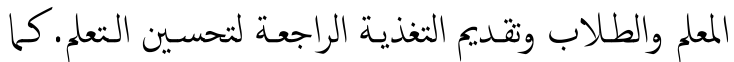

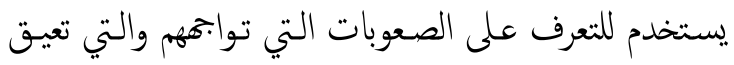

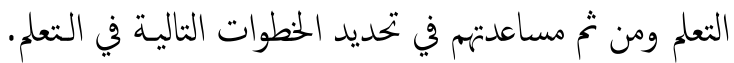
وهذا يحمل الطلاب قدرا من المسؤولية، واكتسـاب مهارات

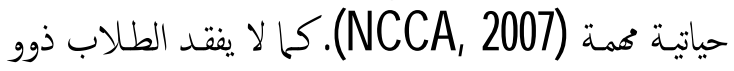
التحصيل المنخفض ثقتهم بأنفسهم لأهم يعلمون أن بإمكانهم

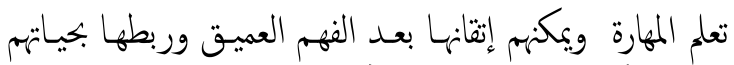
اليومية (Yin, et. al., 2008).

كما أن بطاقة تقدير أداء الطلاب في التقويم الحالي لا تحدد

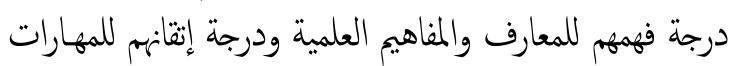

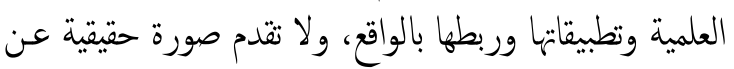

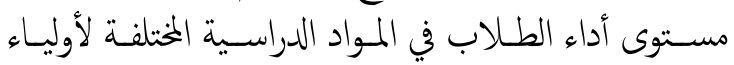

ج" هـل توجد فروق ذات دلالة إحصائية بين آراء أولياء

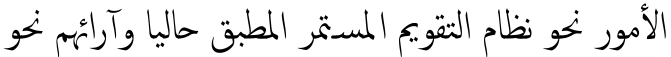

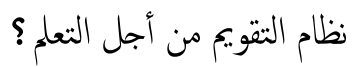

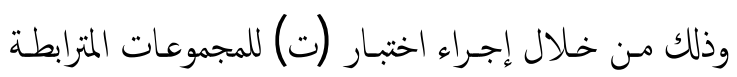

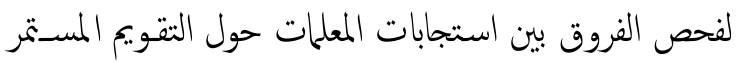

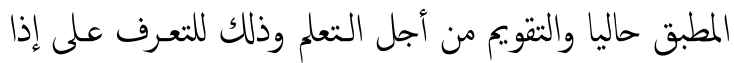

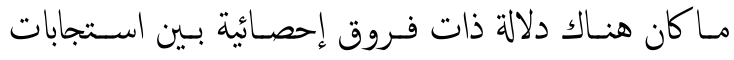

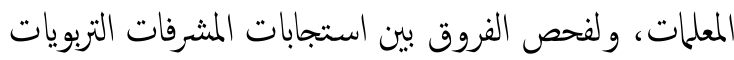

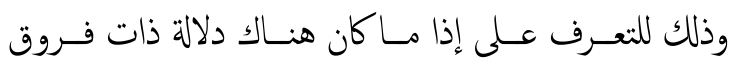

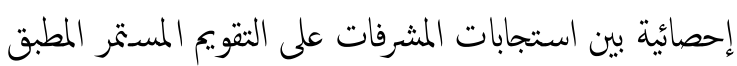

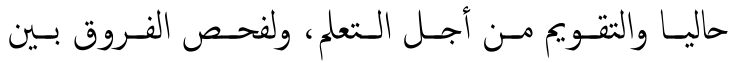

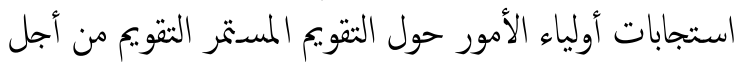

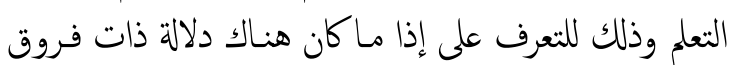

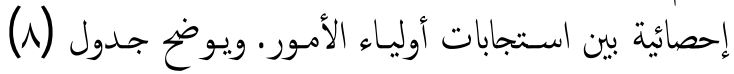
هذه النتأُج. يتضح من جدول ^ وجـود فروق ذات دلالة إحصائية عند

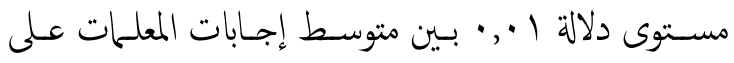

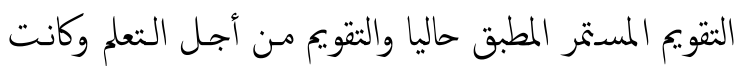

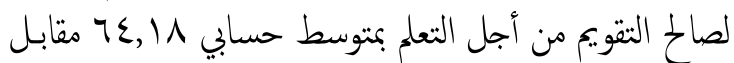

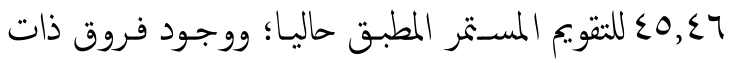

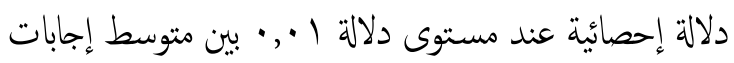

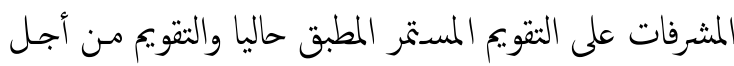

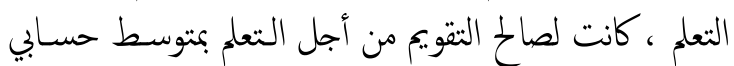

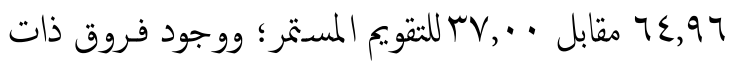

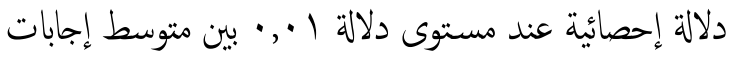

جدول 1

تابُ اختبار (ت) للمجموعات المترابطة لفحص الفروق بين استجابات أفراد العينة (معلمات، ومشرفات، وأولياء أمور) نحو الثقويم المستمر المطبق المبق حاليا والثقويم من أجل التعلم المينة

\begin{tabular}{|c|c|c|c|c|c|c|c|c|}
\hline مستوى الدلالة & الحرية & (ت) & المتوسطات & المعياري & المسابي & 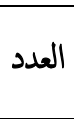 & نوع التقويم & نوع العينة \\
\hline \multirow{2}{*}{$\cdot, \cdot 1$} & \multirow{2}{*}{ rᄉ } & \multirow{2}{*}{7,174} & \multirow{2}{*}{$\mid \Lambda, V Y$} & $11, \cdot r$ & $\{0, \varepsilon 7$ & $r q$ & 'لتقويم المستمر المطبق حاليا & \multirow{2}{*}{ معلمات م } \\
\hline & & & & $\mid r, r \cdot$ & $T \varepsilon, 1 \wedge$ & rq & التقويم من أجل التعلم & \\
\hline \multirow{2}{*}{$\cdot, \cdot 1$} & \multirow{2}{*}{$r q$} & \multirow{2}{*}{$11,0}$. & \multirow{2}{*}{$r V, 97$} & $v, r q$ & $r v_{1} \cdot \cdot$ & $r \cdot$ & 'لتقو.يم المستمر المطبق حاليا & \multirow{2}{*}{ مشرفات } \\
\hline & & & & $1 \cdot, 9$ & $7 \varepsilon, 97$ & $r$. & التقو.يم من أجل التعلم & \\
\hline \multirow{2}{*}{$\cdot, \cdot 1$} & \multirow[t]{2}{*}{ qV } & \multirow{2}{*}{$0,1 \mathrm{~V}$} & \multirow{2}{*}{$T, \varepsilon r$} & $9, \wedge$ & 0,17 & 91 & 'لتقويم المستمر المطبق حاليا & \multirow{2}{*}{ أولياء أمور } \\
\hline & & & & $\Lambda, \mathrm{V}$ & 01,01 & 91 & التقو.يم من أجل التعلم & \\
\hline
\end{tabular}


ع. أضـافت بعض المعلمات . 0\% مـا لاحظتهه مـن

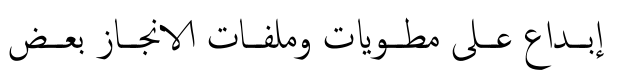
الطالبات. 0. أدى الاستعانة ببطاقة تقدير أداء الطالب المقترحة

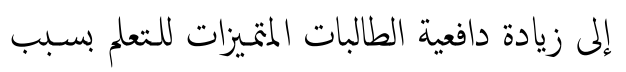

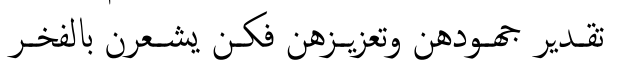

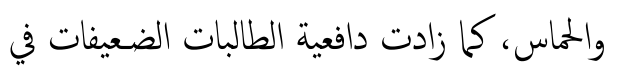

التحصيل لرغبتهن للالتحاق بزميلاتهن المتميزات.

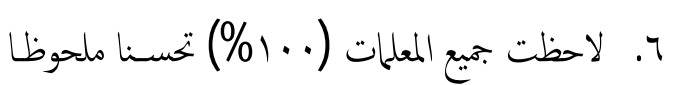

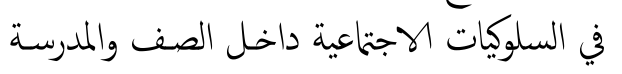

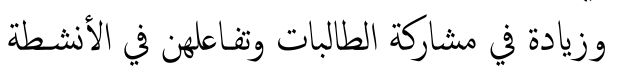

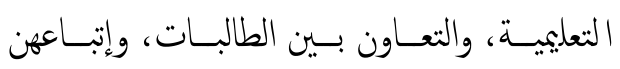

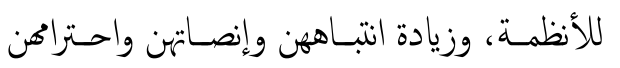

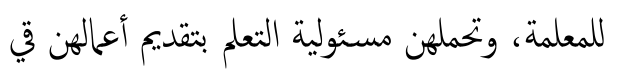

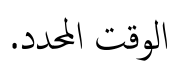

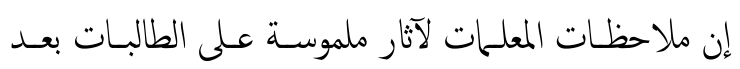

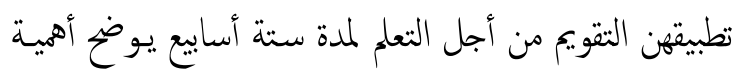

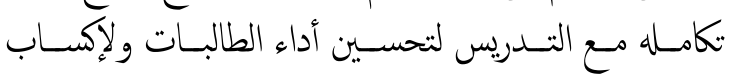
الطالبات محارات حياتية محمة.

التوصيات

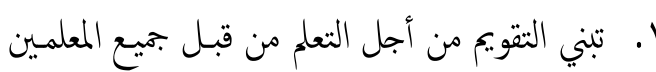
والمعلمات ليتكامل مع تدريس العلوم لتحسين التعلم. r. ت تدريب جميع المعلمين والمعلمات على تطبيق التقويم من أجل النعلم بشكل متكامل مع التدريس.

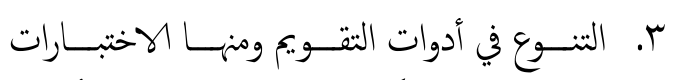

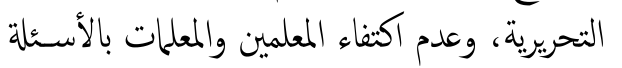

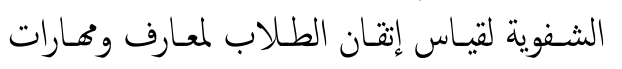
العلوم. ع. التأكيــــــلى أهميـة تقديم المعلم النغذيـة الراجعـة لطلابه، ومنابتهم في تحسين التعلم. 0. اعتاد بطاقة تقدير أداء الطلاب المقترحة مـن قبل

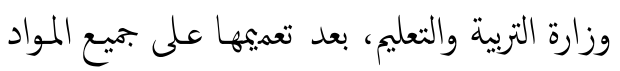
الدراسية بما يناسب طبيعة المادة.

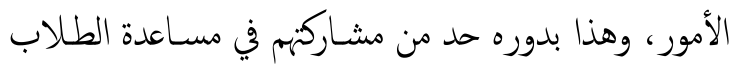

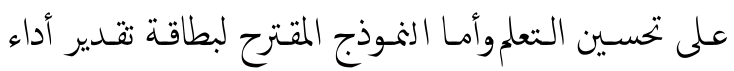

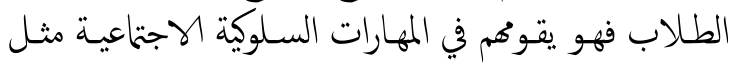

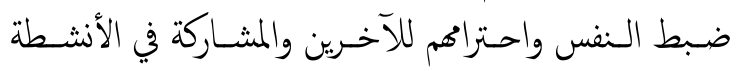

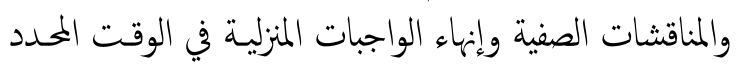

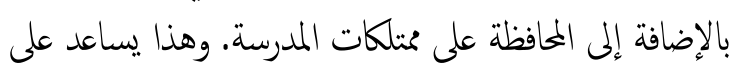

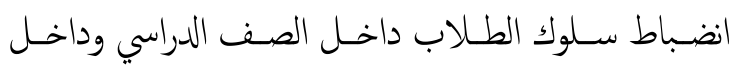

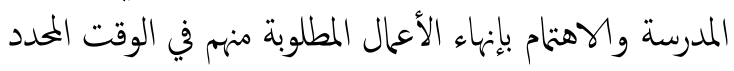

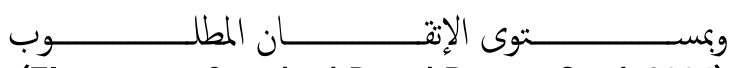
(Elementary Standard-Based Report Card, 2004)

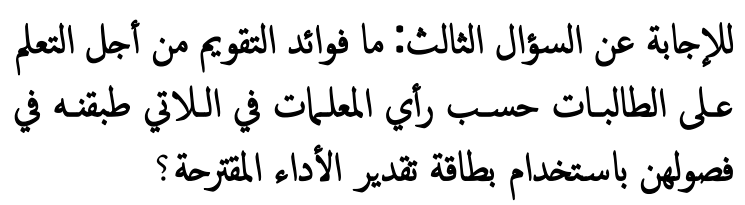
تم تحليل المقابلة الشخصية التي أجريت مع العينة المكونة مـن

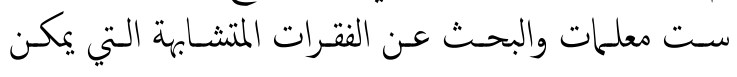

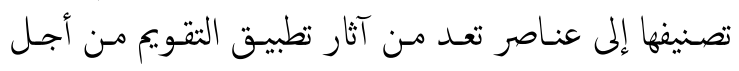
التعلم على الطالبات. وقد أفرز تحليل هذه المقابلات الآتي:

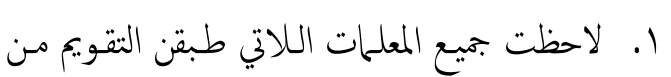

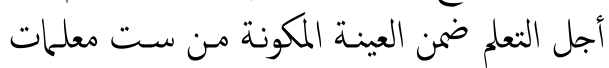

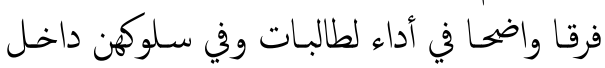

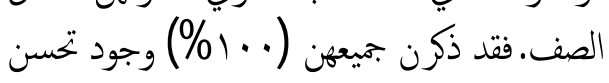

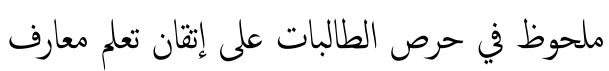

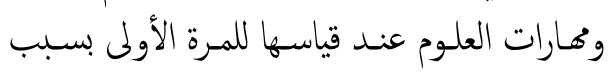
تحسن أدائهن في الأعال الكنابية مثل أوراق العمل فيل الماتل

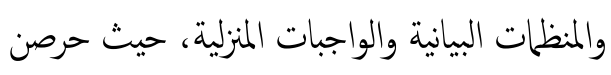

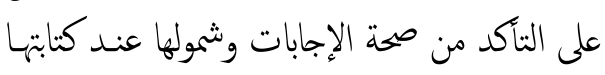

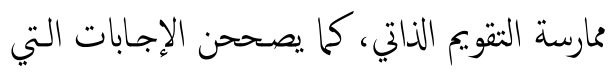

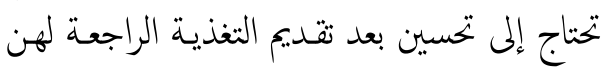
من قبل المعلمة. r. ذذكت 77 \% من معلمات العينة أن بعض طالباتهن

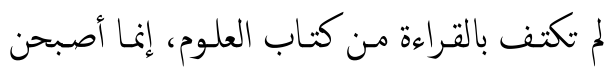

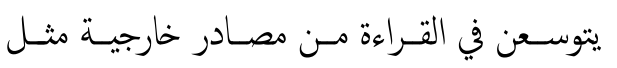
الانترنت للاستزادة.

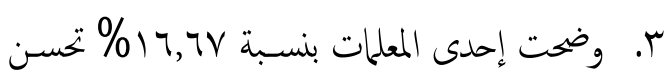

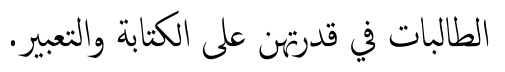




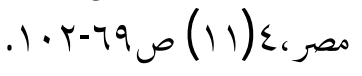

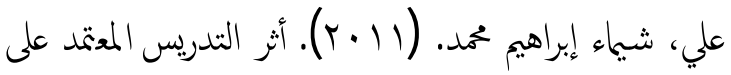

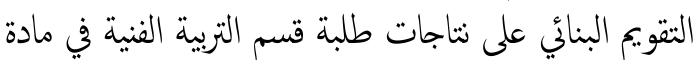

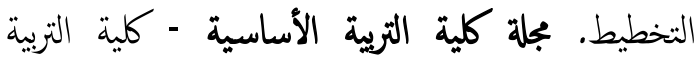

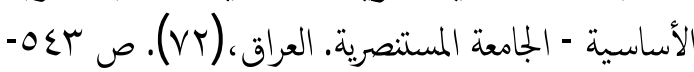
.074

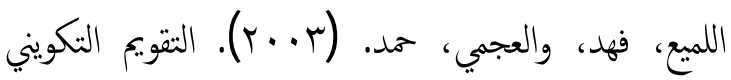

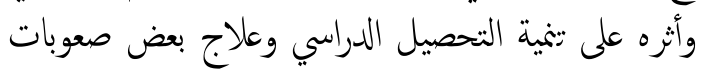

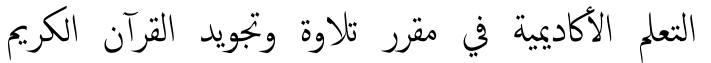
بمدارس ثانوية المقررات بدولة الكويت. دراسات في المناج

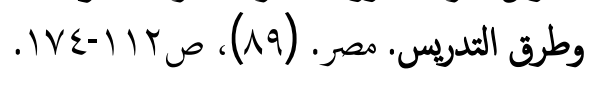

المذكة التفسيرية والقواعد التنفيذية للائحة تقويم الطالب.

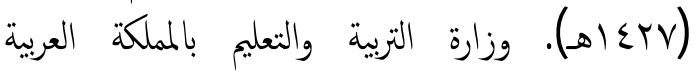

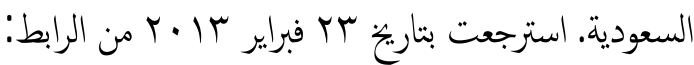
https:/ / www.moe.gov.sa

Bangert-Drowns, R.L., Kulik, C.-C, Kulik, J.A., and Morgan, M. (1991). The instructional effect of feedback in test-like events. Review of Educational Research, 61(2), 213-238.

Black, P., Wiliam, D. (1998). Assessment and classroom learning. A ssessment in Education: Principles, Policy \& Practice, 5 (1), 1-54.

Black, P., Harrison, C., Lee, C., Marshall, B., and Wiliam, D. (2003). A ssessment for learning putting it into practice. New York: Open University Press.

Boston, C. (2002). The concept of formative assessment. Practical A ssessment, Research \& Evaluation, 8(9). Retrieved February 1, 2013 from:

http:/ / PAREonline.net/ getvn.asp?v=8\&n=9

Brown, E., Gibbs, G. and Glover, C. (2003). Evaluation tools for investigating the impact of assessment regimes on student learning. Bioscience Education Electronic journal (BEE-j), 2,5 .

Cappius, S. and Stiggins, R. (2002). Classroom Assessment for learning .Educational Leadership, 60 (1), 40-43.
ا ـ إجراء دراسات تجريبية على أثر التقويم مـن أجل

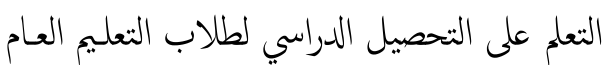
في مدارس المملكة العربية السعودية.

r. إجراء دراسات تجريبية على أثر التقويم من أجل

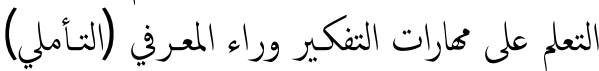

لطلاب التعليم العـام في مـدارس المملكة العربيـة

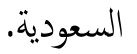

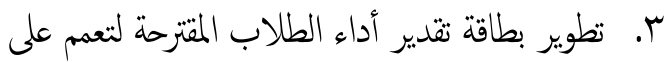

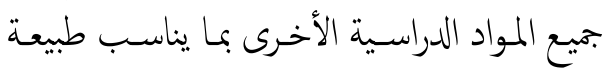

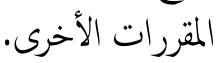

$$
\text { المراجع }
$$

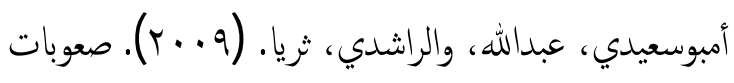

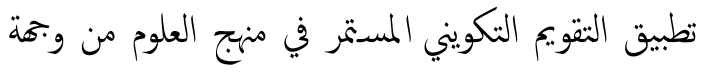
نظر عينة من معلمي العلوم بسلطنة عمان. مجلة العلوم

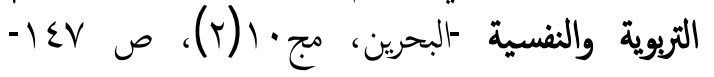
.177

حسن، محمود، (V V ا اهـ)، أثر الثقويم البنائي على التحصيل

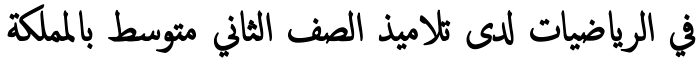

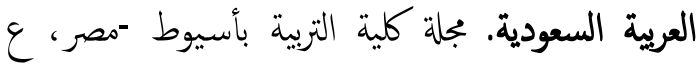
rا

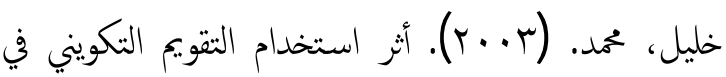
تدريس الأحياء على تنمية التحصيل وهمارات التفكير العلمي

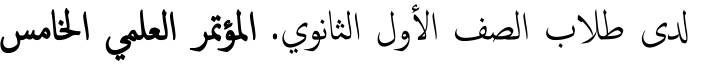

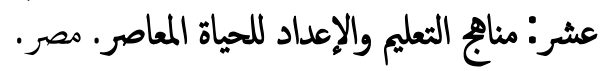
رشوان، أحمد محد علي. (7 ( . ب). فاعلية استخدام التقويم البنائي في تدريس مقرر طرق تدريس العلوم الشرعية في

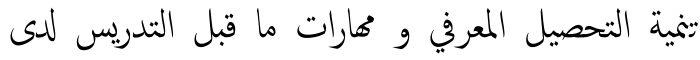

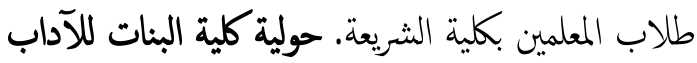

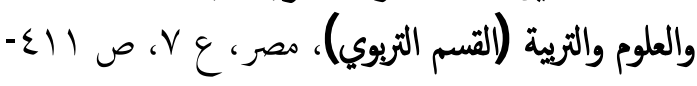
. $₹ \vee q$

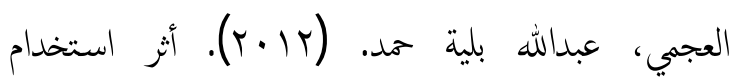
إستراتيجية التقوبم التكويني في تنمية تحصيل الدية الدراسي لطلاب الصف السابع في مادة اللغة العربية، مجلة الطفولة 
Elementary Standard-Based Report Card. (2004). Visalia Unified School District Curriculum / Educational Services. California, USA. Retrieved from:

http:/ / visalia.k12.ca.us/ curriculum/ sbrc/ s brc_manual.pdf

Elshout-Mohr, M. (1994). Feedback in Selfinstruction, European Education, 26, 58-73.

Glastonbury Public Schools. (2010, 2011). Elementary report cards grades K-5. Glastonbury, CT., USA.

Lalley, James P. and Gentile, J. Ronald. (2009). Classroom assessment and grading to assure mastery. Theory into Practice, 48 (1): 28-35.

National Council for Curriculum and A ssessment NCCA. (2007) A ssessment on the Primary School Curriculum, Guidelines for Schools. Dublin.

Barbara C. Jordan Elementary School. Progress Report Grades 4-5. (2012). School District of University City, M issouri, USA.

Richland School District. (2012). Student progress card 5th grade. Richland, Washington, USA.

Ruiz-Primo, M., and Furtak, E. M. (2006). Informal Formative Assessment and Scientific Inquiry: Exploring Teachers' Practices and Student Learning. Educational A ssessment, 11(3-4), 237-263.

Shirbagi, N. and Bahman, K. (2008). Using Different Feedbacks in Formative assessment. Journal of Behavioral Sciences, 18 (1-2).

Shute, V. J. (2008). Focus on Formative Feedback. Review of Educational Research, 78 (1), 153-189.

Simpson-Beck, V. (2011). Assessing classroom assessment techniques. Active Learning in Higher Education, 12(2), 125-132. Doi: 10.1177/ 1469787411402482

Volante, L., and Beckett, D. (2011). Formative assessment and the contemporary classroom: Synergies and tensions between research and practice. Canadian Journal of Education/R evue Canadienne de L'éducation, 34 (2), 239-255.

Webster Groves School District Assessment Plan. (2011). St. Louis, Missouri, USA.
Wiliam, D., Lee, C., Harrison, C., and Black, P. (2004). Teachers developing assessment for learning: impact on student achievement. A ssessment in Education: Principles, Policy \& Practice, 11(1), 49-65. Doi: 10.1080/ 0969594042000208994

Wiliam, D. (2011). What is assessment for learning? Studies in Educational Evaluation, 37(1), 3-14. doi:10.1016/ j.stueduc.2011.03.001

Yin, Y., Shavelson, R, A yala, C., Ruiz-Primo, M., Brandon, P., Furtak, E., Tomita, M. and Young, D. (2008). On the impact of formative assessment on student motivation, achievement, and conceptional change. A pplied M easurement in Education, 21(4), 335359. 